ARTICLE

\title{
High-power lithium-selenium batteries enabled by atomic cobalt electrocatalyst in hollow carbon cathode
}

\author{
Hao Tian (1) 1,2,5, Huajun Tian ${ }^{1,5}$, Shijian Wang ${ }^{1}$, Shuangming Chen ${ }^{3}$, Fan Zhang ${ }^{1}$, Li Song (i) ${ }^{3 凶}$, Hao Liu (i) ${ }^{1 凶}$, \\ Jian Liu (1] ${ }^{2,4 凶} \&$ Guoxiu Wang ${ }^{1 凶}$
}

Selenium cathodes have attracted considerable attention due to high electronic conductivity and volumetric capacity comparable to sulphur cathodes. However, practical development of lithium-selenium batteries has been hindered by the low selenium reaction activity with lithium, high volume changes and rapid capacity fading caused by the shuttle effect of polyselenides. Recently, single atom catalysts have attracted extensive interests in electrochemical energy conversion and storage because of unique electronic and structural properties, maximum atom-utilization efficiency, and outstanding catalytic performances. In this work, we developed a facile route to synthesize cobalt single atoms/nitrogen-doped hollow porous carbon $\left(\mathrm{CO}_{S_{A}-\mathrm{HC}}\right)$. The cobalt single atoms can activate selenium reactivity and immobilize selenium and polyselenides. The as-prepared selenium-carbon ( $\mathrm{Se} @ \mathrm{Co}_{\mathrm{SA}}-\mathrm{HC}$ ) cathodes deliver a high discharge capacity, a superior rate capability, and excellent cycling stability with a Coulombic efficiency of $\sim 100 \%$. This work could open an avenue for achieving long cycle life and high-power lithium-selenium batteries.

\footnotetext{
${ }^{1}$ Faculty of Science, Centre for Clean Energy Technology, School of Mathematical and Physical Sciences, University of Technology Sydney, Broadway, NSW 2007, Australia. ${ }^{2}$ State Key Laboratory of Catalysis, Dalian Institute of Chemical Physics, Chinese Academy of Sciences, 457 Zhongshan Road, 116023 Dalian, China. ${ }^{3}$ National Synchrotron Radiation Laboratory, CAS Centre for Excellence in Nanoscience, University of Science and Technology of China, 230029 Hefei, Anhui, China. ${ }^{4}$ DICP-Surrey Joint Centre for Future Materials, Department of Chemical and Process Engineering, and Advanced Technology Institute, University of Surrey, Guilford, Surrey GU2 7XH, UK. ${ }^{5}$ These authors contributed equally: Hao Tian, Huajun Tian. ${ }^{凶}$ email: song2012@ustc.edu.cn; hao.liu@uts.edu.au; jian.liu@surrey.ac.uk; guoxiu.wang@uts.edu.au
} 
echargeable lithium-ion batteries (LIBs) are considered to be the promising candidates towards sustainable energy storage devices due to its long cycle life, high specific power and energy density ${ }^{1,2}$. However, the energy density of current LIBs can not meet the ever-increasing demands from many emerging applications such as electric vehicles ${ }^{3}$. On one hand, lithium-sulfur ( $\mathrm{Li}-\mathrm{S}$ ) batteries have attracted growing attention because of several advantages such as the natural abundance of sulfur, high specific energy density $\left(2600 \mathrm{~W} \mathrm{~h} \mathrm{~kg}^{-1}\right)$ and high theoretical capacity $\left(1675 \mathrm{~mA} \mathrm{~h} \mathrm{~g}^{-1}\right)^{4}$. However, the development of $\mathrm{Li}-\mathrm{S}$ batteries still suffers from the inherent issues of low electronic conductivity of sulfur and the shuttle effect of polysulfides. As an element in the same group of sulfur in the periodic table, selenium owns similar chemical properties to sulfur and has been considered as an alternative cathode material for lithium-selenium battery because of its high theoretical volumetric capacity $\left(3253 \mathrm{~mA} \mathrm{~h} \mathrm{~cm}^{-3}\right)^{5,6}$. Additionally, the conductivity of Se $\left(1 \times 10^{-3} \mathrm{~S} \mathrm{~m}^{-1}\right)$ is much higher than that of $\mathrm{S}$ $\left(5 \times 10^{-30} \mathrm{~S} \mathrm{~m}^{-1}\right)$, which enables higher active material utilization and better rate capability ${ }^{7}$. However, the Se cathodes also have a dissolution issue associated with high-order lithium selenides $\left(\mathrm{Li}_{2} \mathrm{Se}_{x}, x>4\right)$ and large volume expansion during the charge/discharge process, resulting in a low Se utilization, inferior capacity and short cycle life $\mathrm{e}^{7-9}$.

From the pioneering work by Amine et al. ${ }^{10,11}$, various strategies have been proposed to improve the electrochemical performance of selenium cathode. The most effective method is to incorporate Se particles with electronically conductive materials and encapsulate Se particles within a porous carbon matrix $6,12,13$. For Se/porous carbon composite materials, the charge transfer resistance can be decreased and the shuttle effect of polyselenides can be suppressed because of the high conductivity of carbon matrix and the strong affinity of porous carbon for Se particles? Many porous carbon materials have been studied to construct Se/ porous carbon composites for $\mathrm{Li}-\mathrm{Se}$ batteries, such as carbon nanospheres ${ }^{14,15}$, carbon nanofibers ${ }^{16}$, hierarchical porous carbon ${ }^{17}$ and porous hollow carbon bubbles ${ }^{18}$. However, high-power Li-Se batteries with long cycling performance under high currents have never been reported due to the unsatisfactory performance of Se cathodes.
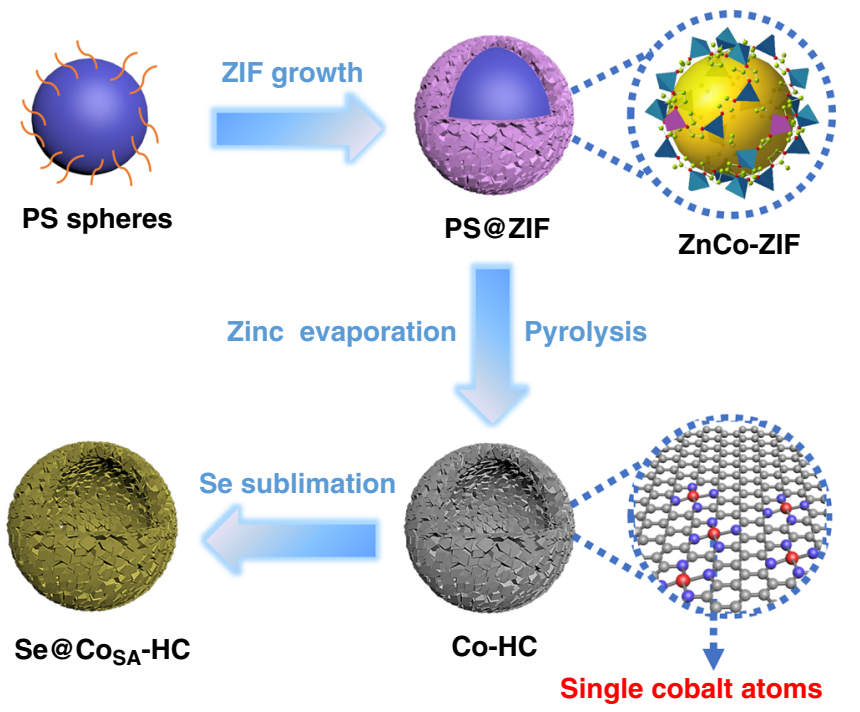

ZnCo-ZIF Carbon particles S PVP O Co O C $\mathrm{N}$

Fig. 1 SAC preparation process. Schematic illustration of the procedures for synthesising cobalt single atoms/nitrogen-doped hollow porous carbon ( $\left.\mathrm{COSA}_{\mathrm{SA}}-\mathrm{HC}\right)$ particles.
Single-atom catalysts (SACs) consist of isolated metal atoms dispersed or anchored on matrix materials. SACs attracted extensive attention due to their maximum atom utilization efficiency, homogenous active centres, and unique reaction mechanisms ${ }^{19-21}$. Currently, SACs have been successfully applied in batteries, including metal-air batteries and metal sulfur batteries $^{22-26}$. In addition, the metal-organic framework (MOF)derived SACs have been intensively investigated in the area of electrocatalysts because of their high electrical conductivity, superior activity, and maximum atomic utilization ${ }^{27-30}$. However, based on literature reviews, as a result of the great challenge of controllable synthesis atomic metals with a selenium host, there has been no report of single atoms in Li-Se batteries, where single atoms can maximize the multi-functions of a selenium host to achieve high rate and cycling performance in a Li-Se battery.

Herein, for the first time, we demonstrate that single-atom catalysts can enable highly effective cathodes for Li-Se batteries with superior rate capability and outstanding long-term cycling performance. A facile and straightforward approach (Fig. 1) facilitates the delicate control of Zeolitic Imidazolate Framework (ZIF) particles deposited on the surface of polystyrene (PS) spheres. More importantly, the core-shell ZIF hybrid structure can be further converted into hollow structured carbon materials via a pyrolysis process with zinc evaporation. Through finely tuning the ratio between $\mathrm{Zn}$ and $\mathrm{Co}$, we successfully prepared atomic cobalt electrocatalyst/nitrogen-doped hollow porous carbon $\left(\mathrm{Co}_{\mathrm{SA}}-\mathrm{HC}\right)$, nitrogen-doped hollow porous carbon $(\mathrm{HC})$ and cobalt nanoparticles/nitrogen-doped hollow porous carbon $\left(\mathrm{Co}_{\mathrm{NP}}-\mathrm{HC}\right)$. In addition, by embedding Se in hollow structured carbon particles, carbon/selenium composites (Se@Co $\mathrm{SA}_{-}-\mathrm{HC}$ ) was obtained. When applied as cathode materials for Li-Se batteries, the Se@Co $\mathrm{SA}_{\mathrm{SA}}-\mathrm{HC}$ cathode exhibited a superior electrochemical performance, including a superior rate capability $\left(311 \mathrm{~mA} \mathrm{~h} \mathrm{~g}^{-1}\right.$ at $50 \mathrm{C}$ ) and excellent cycling stability $\left(267 \mathrm{~mA} \mathrm{~h} \mathrm{~g}^{-1}\right.$ after 5000 cycles with a $0.0067 \%$ capacity decay per cycle at a current density of $50 \mathrm{C}$ ) with the Coulombic efficiency of $\sim 100 \%$. This work reveals that the maximal utilization of cobalt single atoms can optimize the features of porous carbon materials towards the activation of selenium reactivity and immobilization of selenium and polyselenides. Our results demonstrate that the Se@Co $\mathrm{SA}_{\mathrm{A}}-\mathrm{HC}$ composite is a promising cathode material for lithium-selenium batteries with long cycle life and high-power.

\section{Results}

Synthesis and characterization. The synthesis strategy for PS@ZIFs is schematically depicted in Fig. 1. After mixing the PVP-modified PS spheres with zinc nitrate, cobalt nitrate, and 2methyl-imidazolate successively in methanol solution at room temperature, PS@ZIF particles and small ZnCo-ZIFs clusters are formed on the surface of the PS spheres. Three samples with $\mathrm{Zn} /$ Co molar ratios of 20:1, 21:0 and 17:4 have been obtained, designated as PS@ZIF-1, PS@ZIF-2, and PS@ZIF-3, respectively. The growth of ZIF particles on the surface of PS spheres is determined by the interfacial reaction between the substrate and surfactant. Polyvinylpyrrolidone (PVP) plays an important role in the homogeneous growth of ZIFs particles on the surface of PS spheres. To improve electrostatic forces and provide enough coordination sites to uniformly adsorb metal ions, the negatively charged PS spheres are firstly enriched with PVP molecules. The amide carbonyl groups of PVP can fully coordinate with metal ions through chemical bonds and make it possible to achieve the coating of ZIFs on the surfaces of the PS spheres ${ }^{31}$. As shown in Supplementary Fig. 1a, the particle size of the prepared PS@ZIF-1 is about $700 \mathrm{~nm}$ and the particle size of the polyhedral-structured ZIFs on the surface of PS spheres is $\sim 200 \mathrm{~nm}$. The XRD result for 

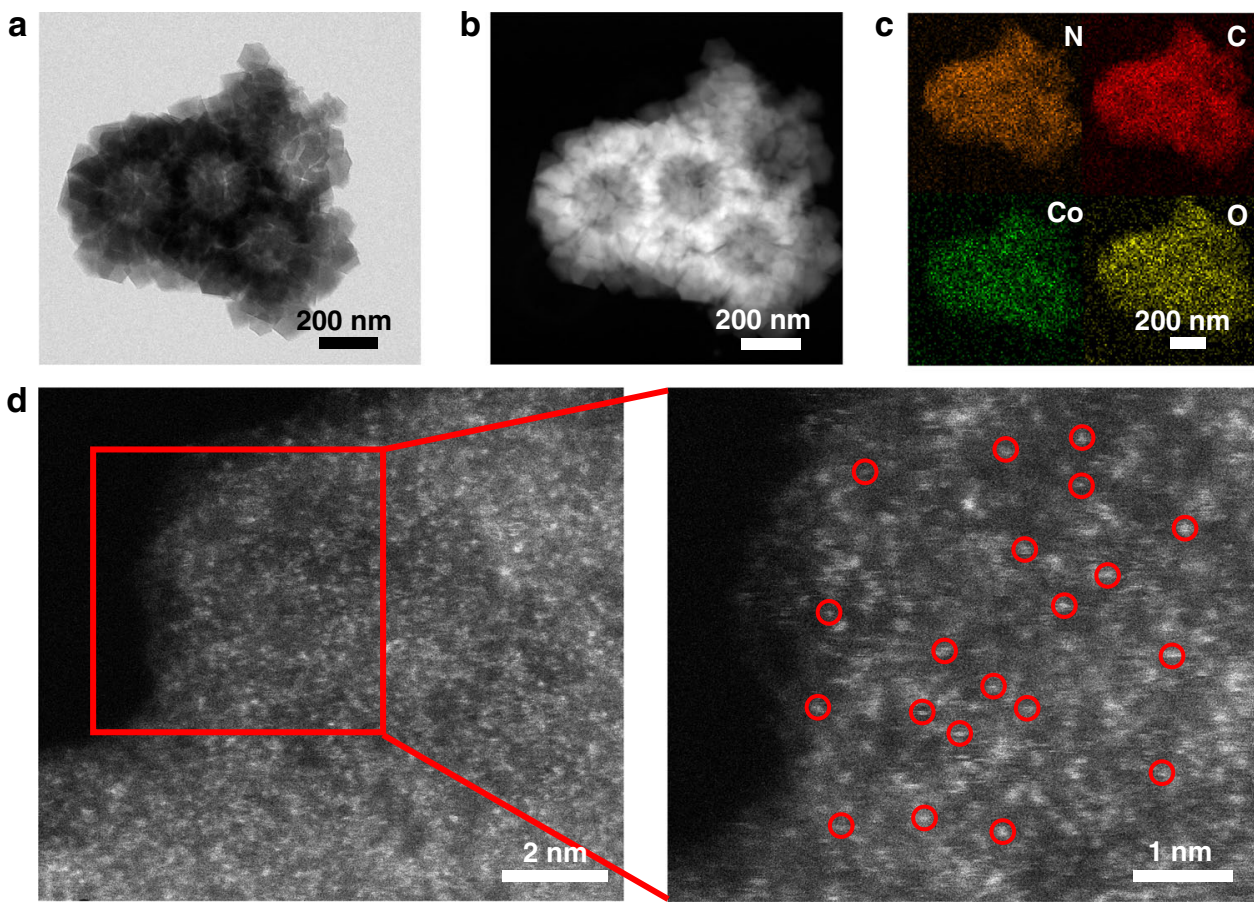

Fig. 2 Representative electron microscopy images. a TEM image, b HAADF image, c STEM element mapping images, $\mathbf{d}$ aberration-corrected HAADFSTEM and magnified images of $\mathrm{COSA}_{\mathrm{A}}-\mathrm{HC}$.

PS@ZIF-1 shown in Supplementary Fig. 2 agrees well with that of as-prepared bimetallic $\mathrm{ZnCo}-\mathrm{ZIFs}^{32}$, confirming the formation of bimetallic ZIF structures. This growth strategy can be extended to the fabrication of other types of ZIFs with different dimensions and components. The SEM images and XRD patterns in Supplementary Fig. 3 show the successful preparation of rGO@ZIF and $\mathrm{MnO}_{2} @ Z I F$. The as-prepared PS@ZIF materials were converted into carbonaceous nanocomposites via one-step pyrolysis. The PS template was removed in situ by evaporation to form a hollow morphology at $70{ }^{\circ} \mathrm{C}$ under a $\mathrm{N}_{2}$ atmosphere. Owing to the composition and size of cobalt in the three products, the obtained carbon materials are denoted Co single atom/nitrogendoped hollow porous carbon $\left(\mathrm{Co}_{\mathrm{SA}}-\mathrm{HC}\right)$, nitrogen-doped hollow carbon (HC) and cobalt nanoparticle/nitrogen-doped hollow porous carbon $\left(\mathrm{Co}_{\mathrm{NP}}-\mathrm{HC}\right)$, respectively. In the previous reports, hollow-structured materials have shown excellent electrochemical performance in energy storage due to large interior voids, high surface area, and shortened mass/charge transport lengths ${ }^{33-37}$. As shown in the SEM image (Supplementary Fig. 4), $\mathrm{Co}_{\mathrm{SA}}-\mathrm{HC}$ particles with a decreased particle size of the polyhedral ZIF particle $\sim 130 \mathrm{~nm}$ were achieved. TEM images (Fig. 2a) and high angle annular dark-field scanning transmission electron microscopy (HAADF-STEM) images (Fig. 2b) also confirmed the hollow nature of the as-prepared carbon materials and no cobalt aggregates are observed, suggesting that the cobalt nanoparticles are anchored uniformly on the carbon matrix. Energy-dispersive $\mathrm{X}$-ray spectroscopy (EDS) images were obtained to identify the elemental distribution of cobalt, nitrogen, oxygen, and carbon. As shown in Fig. 2c, elements are homogenously distributed in the whole carbon framework. From aberration-corrected HAADFSTEM images in Fig. 2d and Supplementary Fig. 5, high-density bright dots (highlighted by red circles) can be detected, revealing the formation of atomic cobalt. The generation of atomically dispersed Co catalysts was attributed to the Co ions being reduced by carbonized organic linkers with the evaporation of elemental $\mathrm{Zn}$ during the calcination process ${ }^{28,38}$. The TEM images in Supplementary Fig. 6 and Supplementary Fig. 7 show that the generation of $\mathrm{HC}$ particles and $\mathrm{Co}_{\mathrm{NP}}-\mathrm{HC}$ particles from pyrolyzed bimetallic ZnCo-ZIFs with Zn/Co molar ratios of 21:0 and $17: 4$. It is revealed that the distance of adjacent Co atoms can be expanded through the introduction of zinc species, achieving the controllable synthesis of different aggregation degrees of atomic Co.

$\mathrm{X}$-ray diffraction (XRD) measurement was performed to investigate the phase structure of $\mathrm{Co}_{\mathrm{SA}}-\mathrm{HC}, \mathrm{HC}$ and $\mathrm{Co}_{\mathrm{NP}}-\mathrm{HC}$ particles (Supplementary Fig. 8). The peaks around $26.8^{\circ}$ and $44.1^{\circ}$ in the XRD pattern of $\mathrm{Co}_{\mathrm{SA}}-\mathrm{HC}$ and $\mathrm{HC}$ particles fit the (002) and (100) planes of graphitic carbon. After increasing the cobalt content in the $\mathrm{Co}_{\mathrm{NP}}-\mathrm{HC}$ particles, newly formed peaks are observed at $44.6^{\circ}, 51.9^{\circ}$ and $76.7^{\circ}$, which can be ascribed to cubic cobalt metal (JCPDS 15-0806). The porosity of the $\mathrm{Co}_{\mathrm{SA}}-\mathrm{HC}$ particles was then studied by nitrogen adsorption-desorption analysis. The $\mathrm{Co}_{\mathrm{SA}}-\mathrm{HC}$ displays mixed type I and IV isotherms (Supplementary Fig. 9a). The sharp adsorption increase in the low-pressure region indicates that the existence of abundant micropores and the hysteresis loop in the medium-pressure region originates from the mesopores with the carbon framework. The pore size distribution of $\mathrm{Co}_{\mathrm{SA}}-\mathrm{HC}$ particles was then analysed based on the isotherms (Supplementary Fig. 9b), which shows peaks centred at 1,17 and $35 \mathrm{~nm}$. The Brunauer-Emmett-Teller (BET) surface area obtained on the basis of the aforementioned adsorption isotherm of $\mathrm{Co}_{\mathrm{SA}}-\mathrm{HC}$, $\mathrm{HC}$ and $\mathrm{Co}_{\mathrm{NP}}-\mathrm{HC}$ are 221,265 and $136 \mathrm{~m}^{2} \mathrm{~g}^{-1}$, respectively. The graphitization degree of a carbon material can be characterized by an $I_{\mathrm{D}} / I_{\mathrm{G}}$ value $\left(I_{\mathrm{D}}\right.$ and $I_{\mathrm{G}}$ represents the intensity of Raman $\mathrm{D}$ and G- bands of carbon materials) in Raman spectra (Supplementary Fig. 10). The ratios for $\mathrm{Co}_{\mathrm{SA}}-\mathrm{HC}, \mathrm{HC}$ and $\mathrm{Co}_{\mathrm{NP}}-\mathrm{HC}$ were $0.99,1.00$ and 1.01 , respectively, indicating the similar graphitic structures in these three hybrids. This allows the exclusion of the influence of carbon supports on electrochemical performance, allowing us to concentrate instead on variances of Co particle size and configuration.

Selenium encapsulation into carbon particles was carried out at $300^{\circ} \mathrm{C}$ under Ar atmosphere to promote the infusion of Se into 

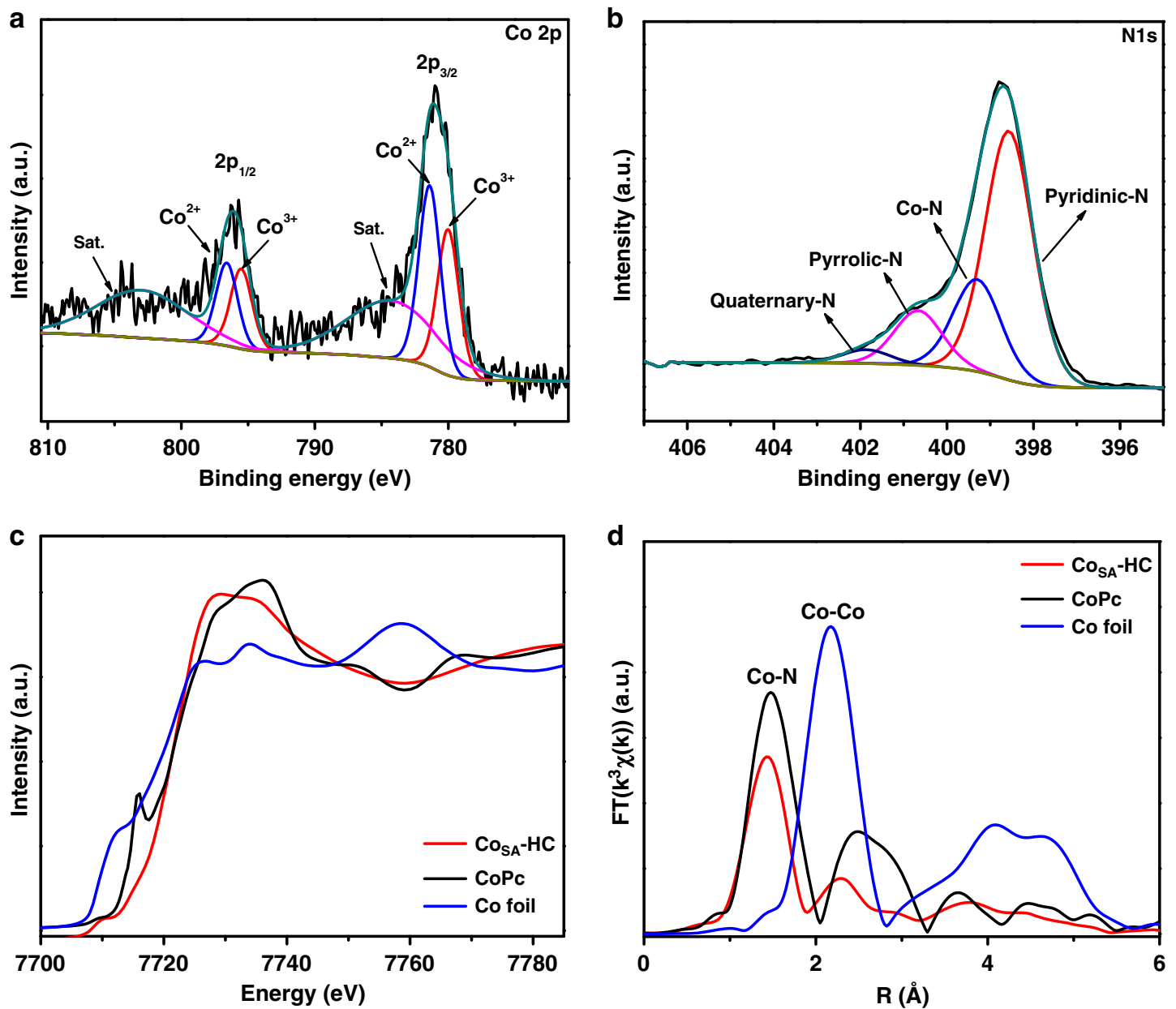

Fig. 3 Structure analysis of the Co SA $_{\mathbf{A}}-\mathrm{HC}$ particles. a Co $2 \mathrm{p}$ and $\mathbf{b} \mathrm{N} 1 \mathrm{~s}$ XPS spectra of $\mathrm{CO}_{\mathrm{SA}_{\mathrm{A}}}-\mathrm{HC}$ particles, $\mathbf{c}$ Co XANES spectra and d Fourier-transform EXAFS spectra of $\mathrm{CO}_{S A}-\mathrm{HC}$, Co foil and Co phthalocyanine (CoPc).

the microporous carbon clusters. The obtained selenium carbon composites are denoted Se@Co $\mathrm{SA}^{-\mathrm{HC}}$, Se@HC and Se@Co $\mathrm{NP}^{-}$ $\mathrm{HC}$, respectively. To obtain a high selenium content in the composite materials, selenium powders were mixed with $\mathrm{HC}$ particles in a weight ratio of 1:3, respectively. SEM images (Supplementary Fig. 11a) and TEM images (Supplementary Fig. 11b) of the as-formed selenium composite material (Se@Co $\mathrm{CA}_{\mathrm{SA}}-\mathrm{HC}$ ) revealed the formation of a size-reduced structure. The HAADF-STEM and EDS images in Supplementary Fig. 11c suggest Se atoms are dispersed uniformly throughout the hollow carbon microstructure. The diffraction peaks of Se in Supplementary Fig. 12 correspond to trigonal crystalline (JCPDS 06-0362) and the XRD pattern of Se@ $\mathrm{Co}_{\mathrm{SA}}-\mathrm{HC}$ (Supplementary Fig. 12) indicated the successful incorporation of Se in the HC carbon matrix. After the selenization process, the crystallinity of selenium is low, which can be attributed to the transformation of trigonal Se to amorphous Se with the formation of low ordering of selenium and successful confinement in the carbon matrix ${ }^{7-9}$. The Se contents in Se@Co $\mathrm{SA}_{-\mathrm{HC}}$, Se@HC, Se@Co $\mathrm{C}_{\mathrm{NP}}-\mathrm{HC}$ and Se@CosA-HC with high Se loading were determined to be 57,55 , 57 and $73 \mathrm{wt} \%$, respectively, through thermogravimetric analysis (TGA) (Supplementary Fig. 13).

Atomic structure analysis. XPS measurements were also used to explore the chemical environment of $\mathrm{Co}_{\mathrm{SA}}-\mathrm{HC}$ particles. The XPS high-resolution $\mathrm{C} 1 \mathrm{~s}$ spectrum of $\mathrm{Co}_{\mathrm{SA}}-\mathrm{HC}$ particles is shown in Supplementary Fig. 14 and can be divided into four individual peaks corresponding to $\mathrm{C}-\mathrm{C}(284.8 \mathrm{eV}), \mathrm{C}-\mathrm{N}(286.2 \mathrm{eV}), \mathrm{C}-\mathrm{O}$ $(287.8 \mathrm{eV})$ and $\mathrm{C}=\mathrm{O}(289.3 \mathrm{eV})^{39,40}$. In the high-resolution Co $2 \mathrm{p}$ spectrum (Fig. 3a), the deconvoluted peaks at $781.4 \mathrm{eV}$ and 796.6 $\mathrm{eV}$ can be ascribed to Co $2 \mathrm{p}_{3 / 2}$ and Co $2 \mathrm{p}_{1 / 2}$ orbitals of $\mathrm{Co}^{2+}$ species and the peaks at $780.0 \mathrm{eV}$ and $795.5 \mathrm{eV}$ correspond to $\mathrm{Co}$ $2 \mathrm{p}_{3 / 2}$ and Co $2 \mathrm{p}_{1 / 2}$ orbitals of $\mathrm{Co}^{3+}$ species ${ }^{28,38}$. The peaks at 784.6 and $802.8 \mathrm{eV}$ are satellite peaks that can be ascribed to the shakeup excitation of the high-spin $\mathrm{Co}^{2+}$ ions ${ }^{36}$. The $\mathrm{N} 1 \mathrm{~s}$ spectrum in Fig. $3 \mathrm{~b}$ can be deconvoluted into four peaks located at $398.6,399.3,400.7$ and $401.8 \mathrm{eV}$, corresponding to pyridinic $\mathrm{N}$, Co-N, pyrrolic $\mathrm{N}$, and quaternary- $\mathrm{N}$, respectively ${ }^{41-43}$. X-ray absorption near-edge structure (XANES) and extended X-ray absorption fine structure measurements (EXAFS) were conducted to investigate the chemical state and coordination environment of $\mathrm{Co}$ atoms in the $\mathrm{Co}_{\mathrm{SA}^{-}}-\mathrm{HC}$ particles. As shown in the XANES spectra (Fig. 3c), the comparison of near-edge adsorption energy with reference cobalt phthalocyanine $(\mathrm{CoPc})$ and Co foil implies that the $\mathrm{Co}$ single atoms in $\mathrm{Co}_{\mathrm{SA}}-\mathrm{HC}$ particles are positively charged, which agrees well with previous results ${ }^{38,44}$. Furthermore, from the EXAFS spectra of the three samples (Fig. 3d), a main peak at $\sim 1.48 \AA$ can be observed for CoPc, which is typically assigned to the $\mathrm{Co}-\mathrm{N}$ tetrahedral coordination $\left(\mathrm{Co}-\mathrm{N}_{4}\right)^{44}$. The Co-N coordination peak shifts to a low R-position at $1.43 \AA$ in the $\mathrm{HC}$ particles, revealing a slightly variation of $\mathrm{Co}-\mathrm{N}$ coordination. Compared with the spectra of HC particles and Co foil, no Co-Co peak around $2.1 \AA$ is observed in $\mathrm{Co}_{\mathrm{SA}}-\mathrm{HC}$ particles, indicating atomically dispersed Co single atoms ${ }^{45,46}$. 

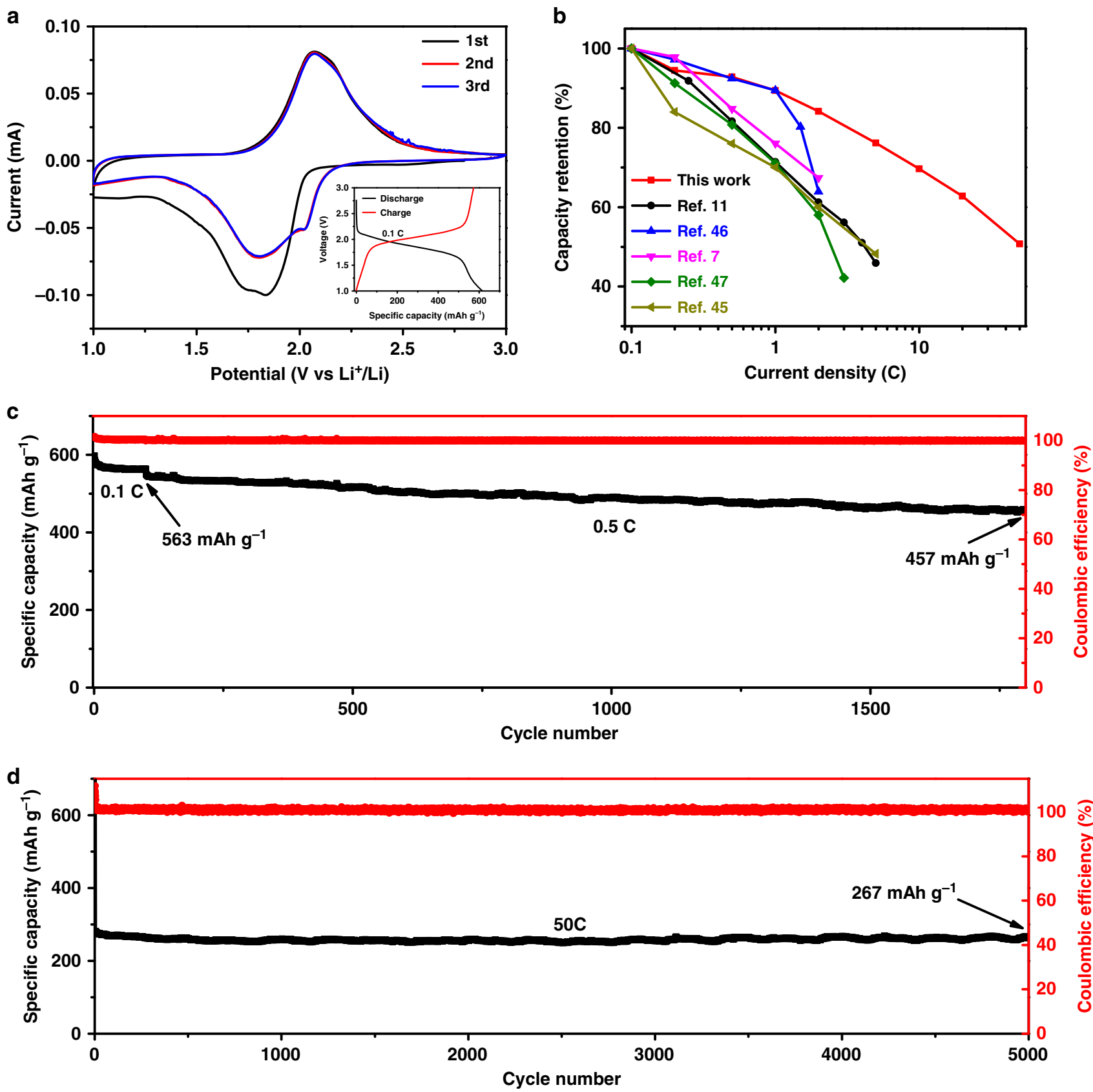

Fig. 4 Lithium-ion-storage behaviour of a Se@CosA-HC cathode. a CV curves of Se@CosA-HC at a scan rate of $0.1 \mathrm{mV} / \mathrm{s}$ (the first three cycles) (inset: discharge-charge voltage profiles of Se@C $\mathrm{S}_{\mathrm{SA}}-\mathrm{HC}$ at $\left.0.1 \mathrm{C}\right) . \mathbf{b}$ The rate capability of Se@C $\mathrm{CO}_{\mathrm{SA}}-\mathrm{HC}$ compared with other reported Se-based electrodes for Li-Se battery. c Cycling performance and Coulombic efficiency at $0.1 \mathrm{C}$ for 100 cycles and then $0.5 \mathrm{C}$ for 1700 cycles. d Long cycling performance and Coulombic efficiency at $50 \mathrm{C}$ for 5000 cycles.

Furthermore, according to the fitting parameters given in Supplementary Table 1 , the Co-N coordination number of $\mathrm{Co}_{\mathrm{SA}}-\mathrm{HC}$ particles is 3.3, implying that the Co-N interaction within $\mathrm{HC}$ particles are consisted of $\mathrm{Co}-\mathrm{N}$ tridentate $\left(\mathrm{Co}-\mathrm{N}_{3}\right)$ and tetrahedral $\left(\mathrm{Co}-\mathrm{N}_{4}\right)$ coordination. Inductively Coupled Plasma Optical Emission Spectrometry (ICP-OES) analysis of $\mathrm{Co}_{\mathrm{SA}_{\mathrm{A}}}-\mathrm{HC}$ particles indicates that the cobalt content was determined to be $\sim 1.3 \%$.

Electrochemical performance. Figure $4 \mathrm{a}$ reveals the cyclic voltammogram $(\mathrm{CV})$ curves of the first three cycles of a Se@Co $\mathrm{SA}^{-}$ $\mathrm{HC}$ electrodes at a scan rate of $0.1 \mathrm{mV} / \mathrm{s}$ between $1.0 \mathrm{~V}$ and $3.0 \mathrm{~V}$. During the first discharge process, two peaks at around 1.74 and
$1.78 \mathrm{~V}$ are observed, which may be related to the lithiation of different Se molecules in the Se@Co $\mathrm{SA}_{\mathrm{S}} \mathrm{HC}$ composites ${ }^{47,48}$. However, these two peaks disappear in the second discharge process, simultaneous with the appearance of two reductions peak at around 1.81 and $2.02 \mathrm{~V}$, resulting from the electrochemical activation behaviour of the Se@Co $\mathrm{SA}_{\mathrm{S}}-\mathrm{HC}$ electrode during the lithiation process ${ }^{16,49}$. During the charge process, there is only one single anodic peak at $2.07 \mathrm{~V}$ in all cycles, and this peak remains stable during following lithiation/delithiation cycles. The $\mathrm{CV}$ curves after the second cycle are overlapping, demonstrating the good electrochemical stability of the Se@ $\mathrm{Co}_{\mathrm{SA}}-\mathrm{HC}$ electrodes. As illustrated in Supplementary Fig. 15, the CV curves after the 10 th and 100th cycle overlap very well at a higher scan rate of 2.0 $\mathrm{mV} / \mathrm{s}$. The inset of Fig. 4a shows the second-cycle galvanostatic 
discharge-charge voltage profiles of Se@ $\mathrm{Co}_{\mathrm{SA}}-\mathrm{HC}$ at the current density of $0.1 \mathrm{C}$. Both discharge and charge processes exhibit stable voltage plateaus at around $2.0 \mathrm{~V}$, which is consistent with the characteristic peaks from the CV curves. The specific capacities of Se@Co $\mathrm{SA}_{\mathrm{A}}-\mathrm{HC}$ electrodes at different current densities as a function of cycle number (from the second cycle) are presented in Supplementary Fig. 16a. The Se@C $\mathrm{Co}_{\mathrm{SA}}-\mathrm{HC}$ electrodes exhibit high specific capacities of $613,579,569,548,516,467,427,385$ and $311 \mathrm{~mA} \mathrm{~h} \mathrm{~g}^{-1}$ at current densities of $0.1,0.2,0.5,1,2,5,10,20$ and $50 \mathrm{C}$, respectively, which are higher than those of Se@HC and Se@Co ${ }_{N P}-H C$ (Supplementary Fig. 16b). When the current rate was returned to $1 \mathrm{C}$, a high discharge capacity of $537 \mathrm{~mA} \mathrm{~h} \mathrm{~g}^{-1}$ could still be attained with almost no capacity degradation, suggesting excellent stability of Se@Co $\mathrm{SA}_{\mathrm{SA}}-\mathrm{HC}$ cathodes. Supplementary Figure 17 shows the discharge and charge profiles of $\mathrm{Se} @ \mathrm{Co}_{\mathrm{SA}^{-}}-\mathrm{HC}, \mathrm{Se} @ \mathrm{HC}$ and $\mathrm{Se} @ \mathrm{Co}_{\mathrm{NP}}-\mathrm{HC}$ at various rates and cycles. It indicates that both discharge and charge processes exhibit stable voltage plateaus at around $2.0 \mathrm{~V}$. Compared with $\mathrm{Se} / \mathrm{rGO}$ and $\mathrm{Se} / \mathrm{MnO}_{2}$ electrodes (Supplementary Fig. 18), $\mathrm{Se} @ \mathrm{Co}_{\mathrm{SA}}-\mathrm{HC}$ cathodes exhibit superior rate electrochemical performances mainly due to the enhanced conductive network, which was previously reported using rGO-based electrodes for $\mathrm{Li}-\mathrm{Se}$ batteries ${ }^{50}$. Supplementary Figure 19 exhibits the rate capability of an unselenated $\mathrm{Co}_{\mathrm{SA}}-\mathrm{HC}$ electrode at different current densities from 0.1 to $5 \mathrm{C}$. It exhibits a much lower specific capacity of $43 \mathrm{~mA} \mathrm{~h} \mathrm{~g}^{-1}$ at $0.1 \mathrm{C}$. This indicates that the capacity contribution from the $\mathrm{Co}_{\mathrm{SA}}-\mathrm{HC}$ matrix alone in the Se@Co $\mathrm{SA}_{\mathrm{SA}}-\mathrm{HC}$ composite is negligible. This superior rate performance exceeds those of the reported Se-based materials, especially at high rates

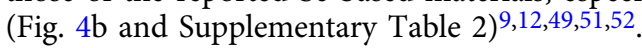

Figure $4 c$, d show the cycling stability of the Se@Co $\mathrm{SA}_{\mathrm{SA}}-\mathrm{HC}$ cathode. After 100 cycles at current density $0.1 \mathrm{C}$ (Fig. 4c), the $\mathrm{Se} @ \mathrm{Co}_{\mathrm{SA}}-\mathrm{HC}$ cathodes delivered a high reversible capacity of 563 $\mathrm{mA} \mathrm{h} \mathrm{g}^{-1}$ with $94 \%$ capacity retention. Figure $4 \mathrm{c}$ further shows the cycling performance of the $\mathrm{Se} @ \mathrm{Co}_{\mathrm{SA}}-\mathrm{HC}$ at a current density of 0.5 C. A large reversible specific capacity of $457 \mathrm{~mA} \mathrm{~h} \mathrm{~g}^{-1}$ was obtained after 1700 cycles. To highlight the role of atomic Co, the cycling stability of the Se@HC and Se@Co $\mathrm{NP}_{\mathrm{NP}}-\mathrm{HC}$ cathodes were also tested, as presented in Supplementary Fig. 20, which indicates the better capacity retention of Se@ $\mathrm{Co}_{\mathrm{SA}}-\mathrm{HC}$. Furthermore, Supplementary Fig. 21 shows the cycling performance of the Se@ $\mathrm{Co}_{\mathrm{SA}}-\mathrm{HC}$ cathode with a high areal loading of selenium about $5 \mathrm{mg} \mathrm{cm}^{-2}$ at $0.2 \mathrm{C}$ for 100 cycles, demonstrating stable cyclability and high capacities. When the selenium mass ratio was increased to $73 \%$ in the composite materials, the resultant Se@ $\mathrm{Co}_{\mathrm{SA}}-\mathrm{HC}$ cathodes with high Se loading delivered $242 \mathrm{~mA} \mathrm{~h} \mathrm{~g}^{-1}$ at $0.2 \mathrm{C}$ after 100 cycles and 220 $\mathrm{mA} \mathrm{h} \mathrm{g}^{-1}$ at $0.5 \mathrm{C}$ after 100 cycles (Supplementary Fig. 22). As a highlight in Supplementary Fig. 23, the Se@Co $\mathrm{SA}_{\mathrm{A}}-\mathrm{HC}$ composite cathode operated for 1500 cycles at $5 \mathrm{C}$ with only $0.015 \%$ capacity decay per cycle from the 10th to the 1500th cycle, along with a Coulombic efficiency of nearly $100 \%$, indicative of a quite stable prolonged cycle life. Moreover, to further demonstrate the long cycle life of Li-Se battery, the long-term cycle life at a high rate of $20 \mathrm{C}$ (Supplementary Fig. 24) and $50 \mathrm{C}$ (Fig. 4d) was also tested. The Se@Co ${ }_{S A}-\mathrm{HC}$ electrodes delivered a remarkable capacity of $237 \mathrm{~mA} \mathrm{~h} \mathrm{~g}^{-1}$ after 2500 cycles with $0.015 \%$ capacity decay per cycle at a current density of $20 \mathrm{C}$ and $267 \mathrm{~mA} \mathrm{~h} \mathrm{~g}^{-1}$ after 5000 cycles with $0.0067 \%$ capacity decay per cycle at a current density of $50 \mathrm{C}$, and both had nearly $100 \%$ Coulombic efficiency. To the best of our knowledge, such an exceedingly good cycling stability of Li-Se batteries especially at high current rates such as $50 \mathrm{C}$ for 5000 cycles has not been reported previously $9,12,49,51,52$.

In order to further clarify the electrochemical processes in Se@Co $\mathrm{CA}_{\mathrm{S}} \mathrm{HC}$ electrodes after the first discharge-charge cycle at 3.0 V, XPS measurements were carried out. Compared with bare $\mathrm{Co}_{\mathrm{SA}}-\mathrm{HC}$, there is a newly formed peak at $290.5 \mathrm{eV}$ in the $\mathrm{C} 1 \mathrm{~s}$
XPS spectrum for Se@Co $\mathrm{SA}_{-}-\mathrm{HC}$ electrodes as shown in Supplementary Fig. 25a. This peak was detected after the first discharge-charge cycle to $3.0 \mathrm{~V}$, indicating the formation of C-Se bonds $7,47,53$. This peak can probably be ascribed to the strong interaction between the Se molecular and the carbon framework or the interaction between Se particles and a carbonyl group ${ }^{7}$. The peaks centred at 55.6 and $56.3 \mathrm{eV}$ in the Se 3d XPS spectrum in Supplementary Fig. $25 \mathrm{~b}$ are attributed to Se $3 d_{5 / 2}$ and $S e 3 d_{3 / 2}$, respectively. In addition, the broad peak located at $59.6 \mathrm{eV}$ is ascribed to C-Se bonding 7,47,53, which is consistent with the results from high-resolution C1s XPS spectra. Only one peak can be deconvoluted from the $\mathrm{N}$ 1s spectrum in Supplementary Fig. 25c. This is the peak located at $400.0 \mathrm{eV}$, which corresponds to pyrrolic $\mathrm{N}$.

To understand the excellent rate capability of Se@Co $\mathrm{CA}_{\mathrm{SA}}-\mathrm{HC}$ in $\mathrm{Li}-\mathrm{Se}$ batteries, the electrochemical kinetics were investigated by $\mathrm{CV}$ measurements at various scan rates from $0.1 \mathrm{mV} / \mathrm{s}$ to $0.5 \mathrm{mV} / \mathrm{s}$. As shown in Fig. 5a, there are two cathodic peaks (denoted as R1 and R2) related to two sequential reactions at $0.1 \mathrm{mV} / \mathrm{s}$. With increasing scan rate to $0.5 \mathrm{mV} / \mathrm{s}$, the peak $\mathrm{R} 1$ becomes dominant, while the intensity of the peak $\mathrm{R} 2$ is relatively weak. At a scan rate of $0.5 \mathrm{mV} / \mathrm{s}$, the $\mathrm{R} 2$ peak in the $\mathrm{CV}$ curve almost disappears. To further analyse the difference in kinetics, the current changes with regard to the scan rates could be analysed via as $\log (i)=\log (a)+b \log (v)$, where $i$ and $v$ are the peak current and scan rate, and $a$ and $b$ are derived parameters ${ }^{54}$. The reaction kinetics can be analysed via the $b$ values. When the $b$-value reaches around 0.5 , a diffusion-limited process is occurring during electrochemical reactions. The electrochemical behaviour is an interface-limited process and more capacitive, then $b$ value is closer to 1 , indicating faster kinetics processes ${ }^{55}$. As shown in Fig. 5b, the fitting curve is almost a linear relationship, and the peak $\mathrm{R} 1$ slope value, peak $\mathrm{R} 2$ slope value, peak $\mathrm{O}$ slope value are calculated to be $0.85,0.85$ and 0.84 , respectively. This indicates that the conversion of $\mathrm{Se}$ into $\mathrm{Li}_{2} \mathrm{Se}$ is faster than that of $\mathrm{Li}_{2} \mathrm{Se}$ into $\mathrm{Se}$ and both conversions are far from being a diffusion-controlled process. Figure $5 \mathrm{c}$ reveals that $85 \%$ of the total capacity is contributed by a capacitive process at a scan rate of $0.5 \mathrm{mV} \mathrm{s}^{-1}$. With an increase in the scan rate, the relative ratio of capacitive contribution to the total capacity gradually increases, as presented in Fig. $5 \mathrm{~d}$. It is believed that the capacitive behaviour is closely related to the degree of electrochemical dynamics or kinetics in battery electrodes ${ }^{56}$. Thus, the high ratio of capacitive-controlled contribution in battery electrodes is highly beneficial for fast transport of lithium ions, which would lead to superior electrochemical performance of rate capability and long-term cyclability.

To further evaluate the electrochemical processes and kinetics of Li-Se reactions when using Se@Co $\mathrm{SA}_{\mathrm{SA}} \mathrm{HC}$ composite cathodes, EIS spectra were collected as a function of the state of discharge/ charge. Supplementary Fig. 26a illustrates the typical discharge/ charge profile of a Li-Se battery using a Se@Co $\mathrm{SA}_{\mathrm{SA}}-\mathrm{HC}$ composite cathode at $0.1 \mathrm{C}$. The EIS spectra of the Se@Co $\mathrm{CA}_{\mathrm{SA}}-\mathrm{HC}$ electrode at various depths (marked in Supplementary Fig. 26a) during the discharge/charge process are shown in Supplementary Fig. 26b. All the results exhibit two depressed or overlapping semicircles followed by a sloping line. For Li-Se batteries based on etherbased electrolyte, the first semicircle and second semicircle in EIS spectra for Li-Se batteries could be ascribed to the charge transfer resistance of Se/C electrode and accumulation of interfacial layer on cathode surface, respectively ${ }^{57}$. Combined with the XPS results in Supplementary Fig. 25, it is proposed that a stable layer formed at the surface of the Se@C $\mathrm{Co}_{\mathrm{SA}}-\mathrm{HC}$ particles during the first lithiation process. Despite the solubility of Se, lithium polyselenides and $\mathrm{Li}_{2} \mathrm{Se}$ in ether-based electrolytes ${ }^{11}$, side reactions have been restricted when using $\mathrm{Se} @ \mathrm{Co}_{\mathrm{SA}}-\mathrm{HC}$ composites and 

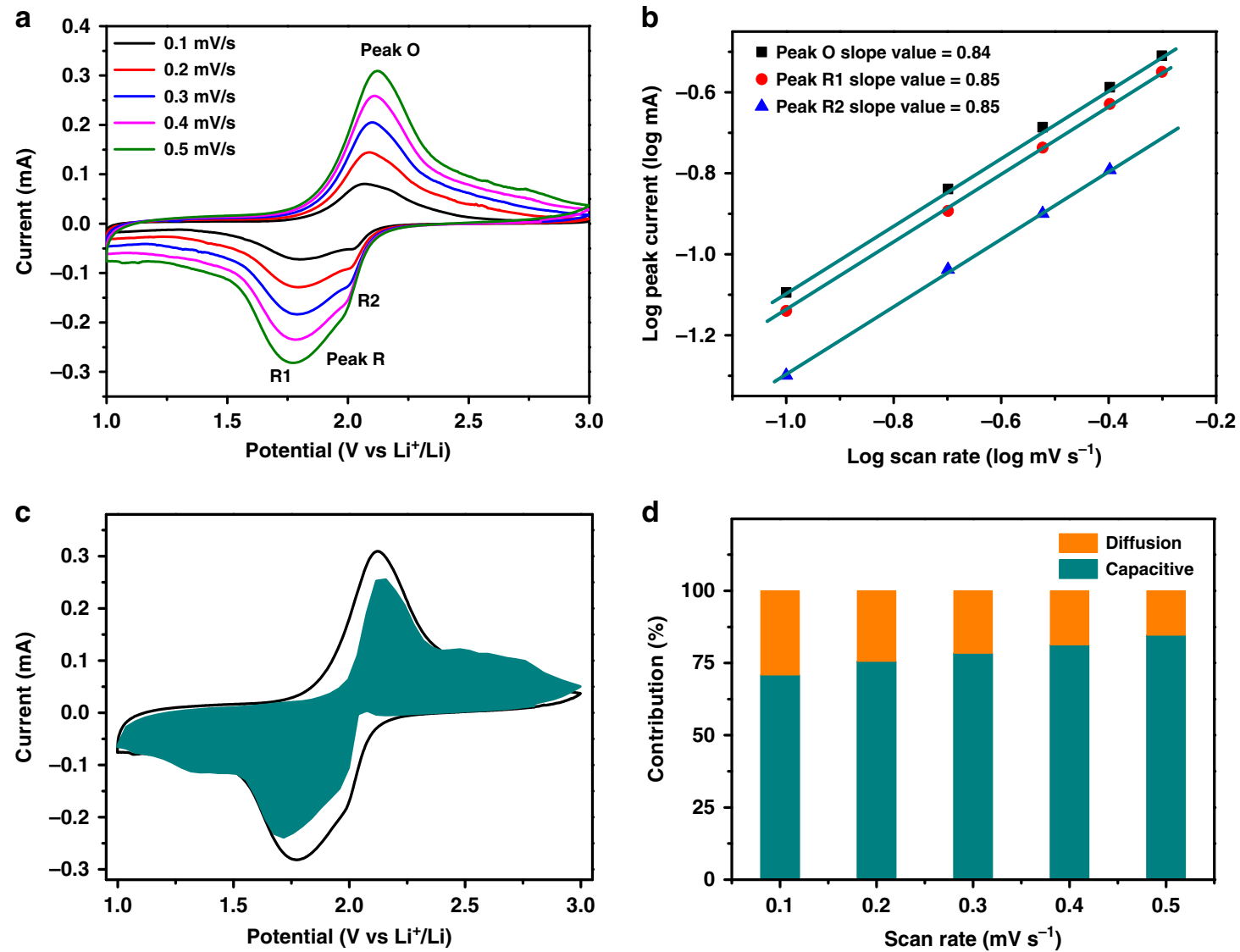

Fig. 5 Kinetic analysis of the electrochemical behaviour of a Se@Co $\mathbf{S A}_{\mathbf{S A}}-\mathbf{H C}$ electrode. a CV curves of Se@CosA $-\mathrm{HC}$ from 0.1 to $0.5 \mathrm{mV} / \mathrm{s}$. b The linear fitting plots of the $\log _{10}$-transformed peak currents versus scan rates. c Contribution of the capacitive process at a scan rate of $0.5 \mathrm{mV} \mathrm{s}{ }^{-1}$. $\mathbf{d}$ Contribution ratio of the capacitive process at different scan rates.

the formed $\mathrm{Li}_{x} \mathrm{Se}$ may be protected from further reaction by the stable layer. The equivalent circuit for fitting is shown in the inset of Supplementary Fig. 26c. In the equivalent circuits, $R_{0}$ represents the impedance that is mainly derived from the resistance of the electrolyte, $R_{1}$ is the charge transfer resistance at the conductive agent interface, and $\mathrm{R}_{2}$ is the resistance of interfacial layer ${ }^{57}$. CPE1 represents double-layer capacitance $\left(\mathrm{C}_{\mathrm{dl}}\right)$, while CPE2 (Constant phase element) describes the space charge capacitance of the layer. $\mathrm{W}_{0}$ is the Warburg impedance corresponding to the polyselenide diffusion processes. The resistance values $\left(R_{1}\right.$ and $\left.R_{2}\right)$ obtained from Supplementary Fig. S26b are summarized in Supplementary Fig. S26c. Supplementary Fig. S27 shows the typical Nyquist plots collected at different discharge-charge state and their fitted curves with two depressed or overlapping semicircles. The obtained resistance values are presented in Supplementary Table 3 . The $R_{1}$ value is relatively stable throughout the whole cycle process, indicating the excellent charge transfer capability. The variation of the charge transfer resistance is attributed to the transformation of crown-like $\mathrm{Se}_{8}$ to $\mathrm{Li}_{2} \mathrm{Se}_{\mathrm{x}}$ during the discharge process, then maintaining amorphous chain-like Se molecules during the charge process. The formation of a stable layer and the reversible Se transformations are responsible for the superior electrochemical performance. The cell with the Se@Co $\mathrm{SA}_{\mathrm{S}}-\mathrm{HC}$ cathode after 1700 cycles was dissembled and the retrieved Se@Co $\mathrm{CA}_{\mathrm{SA}}-\mathrm{HC}$ cathode materials were characterized by TEM. As shown in Supplementary Fig. 28a, it is observed that the morphology of the Se@Co ${ }_{S A}-\mathrm{HC}$ cathode has been well preserved, indicating the superior stability of the cathode structure. From STEM element mapping images in Supplementary Fig. 28c, d, energy-dispersive
X-ray spectroscopy (EDS) images were obtained to identify the elemental distribution of cobalt and selenium, which are homogeneously distributed in the whole carbon framework. As shown in Supplementary Fig. 28b, a homogeneous thin layer with a thickness of $\sim 20 \mathrm{~nm}$ has been identified on the surface of the electrode after long-term cycling. These characterizations confirmed that the composition of the layer could be $\mathrm{Li}_{2} \mathrm{Se}_{2} / \mathrm{Li}_{2} \mathrm{Se}$, which could enhance the cycling performance of the $\mathrm{Li}-\mathrm{Se}$ batteries. This result is consistent with the previously reported literature ${ }^{58}$. Furthermore, EIS spectra were recorded at opencircuit voltage before cycling and after 1st cycle, 2nd cycle, 5th cycle, 10 th cycle and 50th cycle at $0.1 \mathrm{C}$ (Supplementary Fig. 29), 2 C (Supplementary Fig. 30), 5 C (Supplementary Fig. 31) and 20 C (Supplementary Fig. 32). As shown in Supplementary Fig. 2932 , the charge-transfer resistance is very stable after charge/ discharge at various current densities. These results further strengthen our claim that Se@Co $\mathrm{Co}_{\mathrm{SA}}-\mathrm{HC}$ materials possess superior rate performance. Furthermore, it is also found that the diameter of the semicircle at $5 \mathrm{C}$ and $20 \mathrm{C}$ decreases with time, which may be attributed to the further conversion reaction with lithium ions and the stabilization of the layer with increasing cycling time $e^{59}$.

Owing to the electrocatalytic effect resulting from single cobalt atoms within $\mathrm{Co}_{\mathrm{SA}}-\mathrm{HC}$ particles, the $\mathrm{Se} @ \mathrm{Co}_{\mathrm{SA}}-\mathrm{HC}$ electrode shows the lowest overpotentials in charge profiles among the three as-synthesized materials (Fig. 6a). This is in accordance with the smaller value of voltage change $\Delta \mathrm{V}$ (lowest voltage hysteresis) of test cells by using Se@C $\mathrm{Co}_{\mathrm{SA}}-\mathrm{HC}$ to produce discharge-charge curves under a current density of $0.1 \mathrm{C}$ compared with Se@HC and Se@Co $\mathrm{NP}-\mathrm{HC}$, as shown in Fig. 6b. 

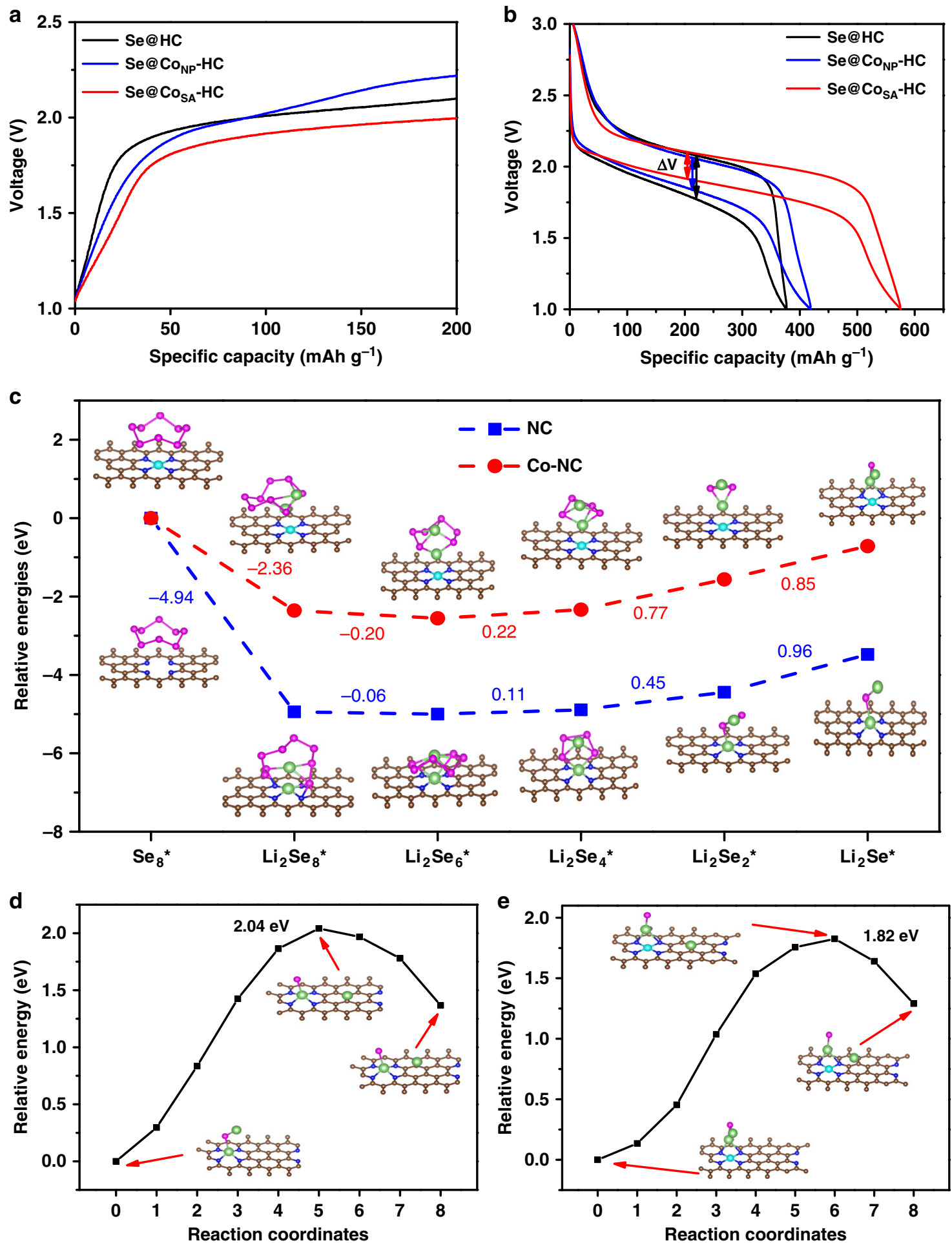

Fig. 6 Catalytic effects of $\mathbf{C o}_{\mathbf{S A}}-\mathbf{H C}$ particles for Li-Se batteries. a The first cycle charge profiles at $0.1 \mathrm{C}$ and $\mathbf{b}$ discharge-charge profile at $0.1 \mathrm{C}$ of Se@Co ${ }_{S A}-\mathrm{HC}$, Se@HC and Se@Co $\mathrm{NP}_{\mathrm{N}}-\mathrm{HC}$. c Energy profiles for the reduction of lithium polyselenides on NC and Co-NC supports (insets: the optimized adsorption conformations of intermediate species on NC and Co-NC substrate). Energy profiles of the transformation of $\mathrm{Li}_{2} \mathrm{Se}$ clusters on $\mathrm{NC}$ (d) and Co-NC (e). (The insets are: the initial, transition, and final structures, respectively.) The brown, pink, green, blue, and cyan balls represent $\mathrm{C}$, Se, Li, N and Co atoms, respectively.

Galvanostatic intermittent titration technique (GITT) testing and EIS spectra were employed to determine the catalyst effect of the single cobalt atoms in $\mathrm{Li}-\mathrm{Se}$ batteries. The GITT plots of Se@Co $\mathrm{SA}_{\mathrm{SA}}-\mathrm{HC}$ and Se@HC (Supplementary Fig. 33a) and the diffusion coefficients $\mathrm{D}_{\mathrm{Li}}{ }^{+}$(Supplementary Fig. 33b) of the Se@Co ${ }_{S A}-\mathrm{HC}$ calculated from GITT plots were estimated to be
$1.02 \times 10^{-13} \sim 1.7 \times 10^{-13}$ (Supplementary Note 1 ), which is almost ten times that of the Se@HC cathode $\left(1.03 \times 10^{-14} \sim\right.$ $8.35 \times 10^{-14}$ (Supplementary Note 1)) material, indicating the better electrochemical kinetics for Se@ $\mathrm{Co}_{\mathrm{SA}}-\mathrm{HC}$ cathode materials in Li-Se batteries. According to the Butler-Volmer equation and EIS spectra (Supplementary Fig. 34), the exchange current 
density $\mathrm{i}_{0}$ of Se@Co $\mathrm{SA}_{\mathrm{SA}}-\mathrm{HC}$ and Se@HC cathode is 1.14 and 0.76 $\mathrm{mA} \mathrm{cm}^{-2}$ (Supplementary Note 2), respectively. To confirm the catalytic role and stability of single cobalt atoms after long-term cycling, the cell after cycled for 1700 cycles was dissembled and the Se@ $\mathrm{Co}_{\mathrm{SA}}-\mathrm{HC}$ cathode was retrieved and characterized. From high angle annular dark-field scanning transmission electron microscopy (HAADF-STEM) images in Supplementary Fig. 35, high-density bright dots (highlighted by red circles) have been clearly detected, revealing that single cobalt atoms in the Se@Co ${ }_{S A}-\mathrm{HC}$ cathode are stable during long-term cycling. All these key kinetic parameters confirm the catalyst effect of the single cobalt atoms.

To further confirm the catalytic activity of single Co atoms after cycling, we conducted a visual observation on the suppression for the formation of lithium polyselenides during the cycling process via single Co atom catalysis. The Se@Co $\mathrm{SA}^{-}$ HC cathode after cycled for 1700 cycles and the cycled bare Se@HC cathode after cycled $0.5 \mathrm{C}$ for 100 cycles were used for the visual observation. As shown in Supplementary Fig. 36a, H-type cell was used in which the cycled Se@Co ${ }_{\mathrm{SA}^{-}}-\mathrm{HC}$ cathode and bare Se@HC cathode were used as the cathode. The electrolyte in the cell with cycled bare Se@HC cathode (Supplementary Fig. 36b, c) changed from colourless to yellow after the first discharge process, implying there was a dissolution of polyselenides in electrolyte ${ }^{60}$. It is clear that by using bare Se@HC cathode without single cobalt catalysts, lithium polyselenides were detached from the cathode and dissolved in the electrolyte, indicating that bare Se@HC cathode owns poor immobilization of polyselenides.

In contrast, the colour change of the electrolyte for the cycled Se@Co ${ }_{\mathrm{SA}^{-}}-\mathrm{HC}$ cathode was not observed during three cycles. Supplementary Fig. 36d, e show that the cell cycled Se@Co $\mathrm{SA}_{\mathrm{SA}}-\mathrm{HC}$ cathode presents transparent electrolyte without colour change, indicating the atomic cobalt electrocatalyst could effectively alleviate the dissolution of polyselenides, maximize polyselenides immobilization, electro-catalyse the transformation from polyselenides to $\mathrm{Li}_{2} \mathrm{Se}$. Therefore, this visual experiment verifies that the single cobalt atoms play an important role that the transformation from polyselenides to $\mathrm{Li}_{2} \mathrm{Se}$ have been electrocatalysed, polyselenides immobilization has been maximized and the dissolution of polyselenides has been inhibited. This visual observation using cycled electrodes clearly confirmed that single atom cobalt catalysts remain active after long cycling.

To further understand the enhancement of reaction kinetics of charge/discharge of the Se@Co $\mathrm{SA}_{\mathrm{S}}-\mathrm{HC}$ cathodes, first-principles calculations were performed to investigate the different possible reactions of lithium polyselenides on nitrogen-doped carbon support (NC) as a reference and atomic Co/nitrogen-doped carbon supports (Co-NC). As shown in Supplementary Fig. 37, two models of nitrogen-doped carbon without and with Co atoms were considered in our simulation. The reversible overall reaction for the formation of $\mathrm{Li}_{2} \mathrm{Se}$ originating from $\mathrm{Se}_{8}$ and $\mathrm{Li}$ was considered $^{12}$. During discharge, the first step involves the reduction of $\mathrm{Se}_{8}$ and the generation of $\mathrm{Li}_{2} \mathrm{Se}_{8}$, followed by further reduction and disproportionation with the formation of three intermediate lithium polyselenides, namely, $\mathrm{Li}_{2} \mathrm{Se}_{6}, \mathrm{Li}_{2} \mathrm{Se}_{4}$, and $\mathrm{Li}_{2} \mathrm{Se}_{2}$, achieving the formation of $\mathrm{Li}_{2} \mathrm{Se}$ as the final product ${ }^{12}$. The Gibbs free energies were calculated for the above reactions on both NC and Co-NC supports (Supplementary Table 4). The optimized structures of the intermediates and their Gibbs free energy profiles are displayed in Fig. $6 \mathrm{c}$. It can be observed that the transformations from $\mathrm{Se}_{8}$ to $\mathrm{Li}_{2} \mathrm{Se}_{6}$ are exothermic and the following three steps involving the conversion of $\mathrm{Li}_{2} \mathrm{Se}_{4}, \mathrm{Li}_{2} \mathrm{Se}_{2}$, and $\mathrm{Li}_{2} \mathrm{Se}$ are endothermic. The largest positive Gibbs free energy can be found in the conversion process from $\mathrm{Li}_{2} \mathrm{Se}_{2}$ to $\mathrm{Li}_{2} \mathrm{Se}$, revealing its role as the rate-determining step in the whole discharge process. The Gibbs free energy of Co-NC support $(0.85 \mathrm{eV})$ is much lower than that of NC support $(0.96 \mathrm{eV})$, indicating that the reduction of Se is thermodynamically more favourable on $\mathrm{Co}-\mathrm{NC}$ than on NC support. In the charging process, the transformation of $\mathrm{Li}_{2} \mathrm{Se}$ is the first step ${ }^{7}$. Through the climbing-image nudged elastic band method, the transformation energy and barrier of $\mathrm{Li}_{2} \mathrm{Se}$ were calculated to evaluate the delithiation reaction kinetics from $\mathrm{Li}_{2} \mathrm{Se}$ to selenium on the surfaces of $\mathrm{Co}-\mathrm{NC}$ and $\mathrm{NC}$ supports. Figure $6 \mathrm{~d}$, e show the energy profiles for the transformation processes on both $\mathrm{Co}-\mathrm{NC}$ and $\mathrm{NC}$ supports. The calculated energy barriers of $\mathrm{Li}_{2} \mathrm{Se}$ transformation of Co-NC supports $(1.82 \mathrm{eV})$ is smaller than that of $\mathrm{NC}(2.04 \mathrm{eV})$, revealing that atomic cobalt nanoparticles are serving as active sites to enhance the phase transformation of $\mathrm{Li}_{2} \mathrm{Se}$ and the Se utilization in $\mathrm{Li}-\mathrm{Se}$ batteries.

In addition, from the DFT calculation results shown in Supplementary Table 5, the Li-Se bond length on the surface of $\mathrm{Co}-\mathrm{NC}$ support is elongated, revealing the interaction between $\mathrm{Li}$ atom and the rest of the molecule is weakened. This leads to the easier delithiation for lithium polyselenides, confirming the role of single Co atom catalysts. Therefore, we proposed a mechanism that single Co atoms can quickly catalyse the transformation from $\mathrm{Li}_{2} \mathrm{Se}_{2}$ into $\mathrm{Li}_{2} \mathrm{Se}$ during the discharging process and the transformation of $\mathrm{Li}_{2} \mathrm{Se}$ during the charging process. To demonstrate the mechanism, the schematic illustration of electrode reaction mechanisms for the Se@Co $\mathrm{CA}_{\mathrm{SA}}-\mathrm{HC}$ cathodes is shown in Supplementary Fig. 38. The confined polyselenides within the carbon framework could be fully reduced into $\mathrm{Li}_{2} \mathrm{Se}$ by single atom Co catalysts, leading to high Se utilization. Therefore, the atomic cobalt on the Co-NC support could effectively alleviate the dissolution of polyselenides, electro-catalyse the transformation from polyselenides to $\mathrm{Li}_{2} \mathrm{Se}$ and minimize the reaction energy barriers, leading to the full utilization of selenium, superior cycling ability, and reversible capability.

\section{Discussion}

Until now, single-atom catalysts were achieved through various strategies, including wet impregnation and coprecipitation methods $^{61}$, atomic layer deposition ${ }^{62}$, pyrolysis ${ }^{63}$ and photodeposition ${ }^{64}$. Among them, pyrolysis is a facile method to construct single-atom catalysts through thermal decomposition of suitable precursors. Herein, we have developed a simple synthesis method to achieve hollow structured particles with isolated, positively charged and highly dispersed single Co atoms through tuning the cobalt and zinc contents from bimetallic $\mathrm{ZnCo}$-ZIFs precursors. The aberration-corrected HAADF-STEM image and EXAFS data provide strong evidence that single Co atoms are high dispersed within the $\mathrm{Co}_{\mathrm{SA}}-\mathrm{HC}$ particles. It is also revealed from XANES results that the single Co atoms are positively charged and the EXAFS data show that isolated single Co atoms can be atomically anchored into the carbon frameworks through the formation of $\mathrm{Co}-\mathrm{N}_{3}$ and $\mathrm{Co}-\mathrm{N}_{4}$ coordination moieties within $\mathrm{Co}_{\mathrm{SA}}-\mathrm{HC}$ particles. By using $\mathrm{Co}_{\mathrm{SA}}-\mathrm{HC}$ particles, more accessible storage sites and larger electrode/electrolyte contact area are provided, and mass/charge transportation lengths are shortened through the formation of the hollow structure. The volume expansion during lithiation can be inhibited by the large internal void spaces.

Based on the density functional theory (DFT) calculations, it indicates that the reaction rate from the reduction of $\mathrm{Li}_{2} \mathrm{Se}_{2}$ into $\mathrm{Li}_{2} \mathrm{Se}$ is noticeably increased during the discharge process by using a single Co atom catalysts. From the charging process data, a smaller value than the calculated energy barriers for $\mathrm{Li}_{2} \mathrm{Se}$ transformation through the single Co atom catalysts can be obtained. It is proposed that the mechanism of single Co atom 
enhancement of $\mathrm{Li}-\mathrm{Se}$ batteries is that single Co atoms can quickly catalyse the transformation from $\mathrm{Li}_{2} \mathrm{Se}_{2}$ into $\mathrm{Li}_{2} \mathrm{Se}$ during the discharging process and the transformation of $\mathrm{Li}_{2} \mathrm{Se}$ during the charging process. Therefore, the atomic cobalt plays the key role in the alleviation of polyselenide dissolution, maximation of polyselenides immobilization and activation via strong electrocatalytic behaviour, achieving the best cycling performance in the field of Li-Se batteries. Therefore, the Se@Co $\mathrm{CA}_{\mathrm{SA}}-\mathrm{HC}$ composite is a promising candidate for long cycle life and high-power lithium-selenium batteries.

In summary, we developed a facile approach for synthesizing core-shell structured PS@ZIF materials which can be further converted into atomic Co electrocatalyst/nitrogen-doped hollow porous carbon $\left(\mathrm{Co}_{\mathrm{SA}}-\mathrm{HC}\right)$ particles through one-step pyrolysis. To highlight the importance of $\mathrm{Co}_{\mathrm{SA}}-\mathrm{HC}$ particles for energy applications, $\mathrm{Co}_{S A}-\mathrm{HC}$ particles were used for $\mathrm{Li}-\mathrm{Se}$ batteries. More specifically, Se@Co ${ }_{S A}-\mathrm{HC}$ cathodes delivered an excellent discharge capacity of $564 \mathrm{~mA} \mathrm{~h} \mathrm{~g}^{-1}$ after 100 cycles at a current density of $0.1 \mathrm{C}$ and a superior rate capability of $385 \mathrm{~mA} \mathrm{~h} \mathrm{~g}^{-1}$ and $311 \mathrm{~mA} \mathrm{hg}^{-1}$ at a current density of $20 \mathrm{C}$ and $50 \mathrm{C}$. In addition, they show a superior reversible capacity of $457 \mathrm{~mA} \mathrm{~h} \mathrm{~g}^{-1}$ at a current density of $0.5 \mathrm{C}$ after 1700 cycles with only $0.011 \%$ capacity decline per cycle and $267 \mathrm{~mA} \mathrm{~h} \mathrm{~g}^{-1}$ after 5000 cycles at $50 \mathrm{C}$ with a $0.0067 \%$ capacity decay per cycle with Coulombic efficiency nearly $100 \%$. These distinctive features of the HC particles are concluded as follows: (i) the atomic cobalt electrocatalyst could effectively alleviate the dissolution of polyselenides, electro-catalyse the transformation from polyselenides to $\mathrm{Li}_{2} \mathrm{Se}$ and minimize the adsorption energy barriers; (ii) the hollow structures provide more accessible selenium storage sites, larger electrode/electrolyte contact area, shortened mass/ charge transport lengths; (iii) the large internal void spaces accommodate volume expansion during lithiation; (iv) the conductive carbon materials enhance the electrode conductivity and effectively confine the soluble polyselenides. This work provides an efficient route for the preparation of single-atom materials and paves a new strategy for developing high-power electrochemical energy storage devices.

\footnotetext{
Methods

Materials. The following provides information on chemicals used in this work: methanol (99\%), styrene, potassium persulfate (KPS), polyvinylpyrrolidone (PVP, $\mathrm{MW} 50,000)$, ethanol (95-100\%), zinc nitrate hexahydrate $\left(\mathrm{Zn}\left(\mathrm{NO}_{3}\right)_{2} \cdot 6 \mathrm{H}_{2} \mathrm{O}\right)$, cobalt nitrate hexahydrate $\left(\mathrm{Co}\left(\mathrm{NO}_{3}\right)_{2} \cdot 6 \mathrm{H}_{2} \mathrm{O}\right)$, 2-methylimidazole were purchased from Sigma-Aldrich and used as received without any further purification. Washing was achieved with ultrapure water and reagent grade ethanol where required. Ultrapure water was used for solution preparations.

Synthesis of polystyrene spheres (PS). The styrene was firstly treated by passing through a column containing neutral alumina to remove polymerization inhibitor and then subjected to vacuum distillation to obtain a purified styrene monomer. $1.1 \mathrm{~g}$ of PVP was dissolved in $100 \mathrm{~mL}$ deionized water, and then $13 \mathrm{~mL}$ of the above treated styrene was added to the solution. After stirring for $30 \mathrm{mins}$, an aqueous 20 $\mathrm{mL}$ solution containing $0.3 \mathrm{~g}$ of potassium persulfate (KPS) was then added to the above mixture. Then the mixture was heated to $70^{\circ} \mathrm{C}$ and remained at this temperature for $24 \mathrm{~h}$.
}

Synthesis of PS@ZIF. In a typical procedure, $0.15 \mathrm{~g}$ of as-prepared PS spheres were fully ground and then dispersed into $90 \mathrm{~mL}$ of methanol containing $1 \mathrm{~g}$ of PVP. After ultrasonic dispersion and vigorous agitation for $3 \mathrm{~h}, 2.125 \mathrm{~g}$ of $\mathrm{Zn}$ $\left(\mathrm{NO}_{3}\right)_{2} \cdot 6 \mathrm{H}_{2} \mathrm{O}$ and $0.104 \mathrm{~g}$ of $\mathrm{Co}\left(\mathrm{NO}_{3}\right)_{2} \cdot 6 \mathrm{H}_{2} \mathrm{O}$ (the molar ratio of $\mathrm{Zn}^{2+} / \mathrm{Co}^{2+}$ was 20 were subsequently dissolved into the mixed solution and stirred for another $0.5 \mathrm{~h}$. Then, $4.926 \mathrm{~g}$ of 2 -methylimidazole dissolved in $90 \mathrm{~mL}$ of methanol was quickly added into the above solution followed by vigorous stirring for $4 \mathrm{~h}$. Finally, the PS@ZIF-1 precursor were collected by centrifugation, washed with methanol for several times, and dried at $60^{\circ} \mathrm{C}$ overnight. Similarly, for the synthesis of PS@ZIF-2 and PS@ZIF-3, the procedures were carried out except that the Zn/Co molar ratio was 1:0 and 17:4, respectively.

Synthesis of $\mathrm{Co}_{\mathrm{SA}}-\mathbf{H C}, \mathbf{H C}, \mathbf{C O}_{\mathbf{N P}}-\mathbf{H C}$ particles. PS@ZIF particles (PS@ZIF-1, PS@ZIF-2 and PS@ZIF-3) were carbonized in flowing $\mathrm{N}_{2}$ in a tube furnace using a heating rate of $5^{\circ} \mathrm{C} \min ^{-1}$ up to $700^{\circ} \mathrm{C}$ and dwelling for $5 \mathrm{~h}$. After naturally cooling down to room temperature, the products were collected and marked as $\mathrm{Co}_{\mathrm{SA}}-\mathrm{HC}, \mathrm{HC}$ and $\mathrm{Co}_{\mathrm{NP}}-\mathrm{HC}$ particles according to the $\mathrm{Zn} / \mathrm{Co}$ molar ratio in the precursors, respectively.

Synthesis of selenium carbon composites. Se powder (99.99\%, Sigma-Aldrich) and the as-prepared $\mathrm{Co}_{\mathrm{SA}}-\mathrm{HC}, \mathrm{HC}, \mathrm{Co}_{\mathrm{NP}}-\mathrm{HC}$ particles with a weight ratio of $1: 1$ were mixed. Subsequently, the mixture was heated at $300^{\circ} \mathrm{C}$ for $12 \mathrm{~h}$ with heating rate of $5{ }^{\circ} \mathrm{C} \mathrm{min}-1$ in a tubular furnace under argon atmosphere to achieve selenium carbon composites. The as-prepared materials were named Se@Co $\mathrm{CA}_{\mathrm{SA}}-\mathrm{HC}$, $\mathrm{Se} @ \mathrm{HC}$ and Se@Co $\mathrm{NP}-\mathrm{HC}$ based on the different carbon precursors.

To achieve high selenium mass ratio in selenium carbon composite, Se powder and the as-prepared $\mathrm{Co}_{\mathrm{SA}}-\mathrm{HC}$ particles with a weight ratio of 3:1 were mixed, followed by the same heat treatment as described above.

Synthesis procedures of rGO@ZIF and $\mathbf{M n O}_{\mathbf{2}} @ Z$ ZIFs. Synthesis of $\mathrm{MnO}_{2}$ nanowires: in a typical synthesis, $50 \mathrm{mg}$ of polyvinylpyrrolidone (PVP) and $40 \mathrm{~mL}$ of $0.015 \mathrm{M} \mathrm{KMnO}_{4}$ aqueous solution were mixed with magnetic stirring, and then the mixture was transferred into a $50 \mathrm{~mL}$ Teflon-lined stainless autoclave. The autoclave was sealed and put in an electronic oven at $160^{\circ} \mathrm{C}$ for $9 \mathrm{~h}$ and then naturally cooled down to room temperature. The precipitates were collected by filtration, washed with deionized water and absolute ethanol several times before drying at $60^{\circ} \mathrm{C}$ overnight.

Synthesis of reduced graphene oxide ( $(G O)$ : Graphene oxide $(3 \mathrm{mg} / \mathrm{ml})$ solution were dried via lyophilization and then was ground into powder. Reduced graphene oxide can be obtained through hydrothermal treatment of graphene oxide $(0.4 \mathrm{~g})$ with $400 \mu \mathrm{L}$ hydrazine hydrate at $95^{\circ} \mathrm{C}$ for $24 \mathrm{~h}$.

Synthesis of the $\mathrm{MnO}_{2} @ Z I F:$ in a typical procedure, $0.07 \mathrm{~g}$ of as-prepared $\mathrm{MnO}_{2}$ nanowires were fully ground and then dispersed into $90 \mathrm{~mL}$ of methanol containing $1 \mathrm{~g}$ of PVP (K-30). After ultrasonic dispersion and vigorous agitation for $3 \mathrm{~h}, 2.125 \mathrm{~g}$ of $\mathrm{Zn}\left(\mathrm{NO}_{3}\right)_{2} \cdot 6 \mathrm{H}_{2} \mathrm{O}$ and $0.104 \mathrm{~g}$ of $\mathrm{Co}\left(\mathrm{NO}_{3}\right)_{2} \cdot 6 \mathrm{H}_{2} \mathrm{O}$ (the molar ratio of $\mathrm{Zn}^{2+} / \mathrm{Co}^{2+}$ was 20 were subsequently dissolved into the mixed solution and stirred for another $0.5 \mathrm{~h}$. Then, $4.926 \mathrm{~g}$ of 2-methylimidazole dissolved in $90 \mathrm{~mL}$ of methanol was quickly added into the above solution followed by vigorous stirring for $4 \mathrm{~h}$. Finally, the $\mathrm{MnO}_{2} @ Z I F$ precursors were collected by centrifugation, washed with methanol for several times, and dried at $60^{\circ} \mathrm{C}$ overnight.

Synthesis of rGO@ZIF: in a typical procedure, $0.07 \mathrm{~g}$ of as-prepared rGO were fully ground and then dispersed into $90 \mathrm{~mL}$ of methanol containing $1 \mathrm{~g}$ of PVP (K30). After ultrasonic dispersion and vigorous agitation for $3 \mathrm{~h}, 2.125 \mathrm{~g}$ of $\mathrm{Zn}$ $\left(\mathrm{NO}_{3}\right)_{2} \cdot 6 \mathrm{H}_{2} \mathrm{O}$ and $0.104 \mathrm{~g}$ of $\mathrm{Co}\left(\mathrm{NO}_{3}\right)_{2} \cdot 6 \mathrm{H}_{2} \mathrm{O}$ (the molar ratio of $\mathrm{Zn}^{2+} / \mathrm{Co}^{2+}$ was 20 were subsequently dissolved into the mixed solution and stirred for another 0.5 h. Then, $4.926 \mathrm{~g}$ of 2-methylimidazole dissolved in $90 \mathrm{~mL}$ of methanol was quickly added into the above solution followed by vigorous stirring for $4 \mathrm{~h}$. Finally, the rGO@ZIF precursors were collected by centrifugation, washed with methanol for several times, and dried at $60{ }^{\circ} \mathrm{C}$ overnight.

Electrochemical measurements. Electrodes were prepared by mixing the selenium carbon composite, carbon black and polyvinylidene fluoride at a weight ratio of 8:1:1 in N-methyl-2-pyrrolidone solvent, The slurry was pasted onto aluminium foil and dried in a vacuum oven at $60{ }^{\circ} \mathrm{C}$ for $12 \mathrm{~h}$. CR2032 coin cells were assembled in an argon-filled glove box (Mbraun, Unilab, Germany) and then used for electrochemical evaluation. The electrolyte contained $1 \mathrm{wt} \%$ lithium nitrate $\left(\mathrm{LiNO}_{3}\right)$ in 1,3-dioxolane and 1,2-dimethoxyethane (volume ratio 1:1). Porous polypropylene (Celgard $2300^{\mathrm{TM}}$ ) was used for the separator membranes. About 20 $\mu \mathrm{L}$ electrolyte was added for each coin cell. The areal loading of selenium in the cathode is $0.8 \mathrm{mg} \mathrm{cm}^{-2}$. The cells were discharged and charged galvanostatically in the fixed voltage range $1.00-3.00 \mathrm{~V}$ with current rates of $0.1-50 \mathrm{C}$ rate using a NEWARE battery tester. Cyclic voltammetry $(\mathrm{CV})$ and electrochemical impedance spectroscopy (EIS) were performed on a Biologic VMP3 electrochemical station. $\mathrm{CV}$ responses were also tested in voltage range $1.00 \mathrm{~V}$ to $3.00 \mathrm{~V}\left(\mathrm{vs} . \mathrm{Li}^{+} / \mathrm{Li}\right.$ ) at scan rate from 0.1 to $0.5 \mathrm{mV} \mathrm{s}^{-1}$. EIS ( $100 \mathrm{kHz}$ to $10 \mathrm{mHz}$ with an amplitude of $5 \mathrm{mV}$ ) Analysis was then applied to evaluate electrochemical behaviors of the electrode.

Materials characterization. The morphology and chemical composition of the asprepared samples were observed by field emission scanning electron microscopy (FESEM, Zeiss Supra 55VP), transmission electron microscopy (TEM, Tecnai G2 F30 S-TWIN). X-ray diffraction (XRD) measurements were carried out by using a scanning step of $0.04^{\circ}$ per second in the $2 \theta$ range from $10^{\circ}$ to $80^{\circ}$ (Bruker D8 Discovery XRD). X-ray photoelectron spectroscopy (XPS) measurements were performed on an ESCALAB250Xi (Thermo Scientific, UK) equipped with monochromated Al K alpha (energy $1486.68 \mathrm{eV}$ ). The BET specific surface area and single-point pore volume were obtained from nitrogen adsorption isotherms measured at $-196^{\circ} \mathrm{C}$ using a nitrogen sorption instrument (ASAP 2460 Micropore Physisorption Analyzer). Prior to nitrogen adsorption measurements, the samples were degassed at $250^{\circ} \mathrm{C}$ overnight. Raman spectra were obtained from a Renishaw inVia Raman spectrometer system (Gloucestershire, UK) equipped with a Leica DMLB microscope (Wetzlar, Germany) and a Renishaw He-Ne laser source producing $17 \mathrm{~mW}$ at $633 \mathrm{~nm}$. Thermogravimetric analysis (TGA) was performed with a 2960 SDT system. X-ray absorption fine structure (XAFS) measurements of the 
Co K-edge were performed at the 1W1B beamline of the Beijing Synchrotron Radiation Facility (BSRF) in transmission mode. The X-ray was monochromatized using a double-crystal $\mathrm{Si}$ (111) monochromator and the energy was calibrated by a cobalt metal foil for Co K-edge. Cobalt foil and CoPc were used as the reference substance. The XAFS data was analysed using the WinXAS3.1 program. Cobalt content in HC particles was determined by Inductively Coupled Plasma Optical Emission Spectrometry (ICP-OES).

Computational method and models. All calculations were carried out by using the projector augmented wave method in the framework of DFT ${ }^{65}$, as implemented in the Vienna $a b$-initio Simulation Package (VASP). The generalized gradient approximation (GGA) and Perdew-Burke-Ernzerhof (PBE) exchange functional ${ }^{65}$ were used. Structural relaxation calculations were performed by using the spinpolarized GGA method ${ }^{66}$. A supercell of graphene containing $4 \times 2 \sqrt{3}$ unit cells was used to model N-G and Co-N-G systems. After convergence tests, the planewave energy cutoff was set to $500 \mathrm{eV}$, and the Monkhorst-Pack method ${ }^{67}$ with $2 \times$ $3 \times 1$ supercells was employed for the Brillouin zone sampling of $\mathrm{N}-\mathrm{G}$ and $\mathrm{Co}-\mathrm{N}-$ $\mathrm{G}$ systems. The convergence criterions of energy and force calculations were set to $10^{-5} \mathrm{eV} /$ atom and $0.01 \mathrm{eV}^{-1}$, respectively. The Gibbs free energies for electrochemical reduction of molecular $\mathrm{Se}_{8}$ and polyselenide $\mathrm{Li}_{2} \mathrm{Se}_{\mathrm{n}}$ on the N-G and Co-N-G systems were calculated by the DFT energy difference between two different reduction steps ${ }^{68,69}$. The DFT-D2 empirical correction method was employed to describe van der Waals interactions. The barriers for $\mathrm{Li}_{2} \mathrm{Se}$ transformation on N/G and Co-N/G were calculated with the nudged elastic band (NEB) method to evaluate its delithiation reaction kinetics.

\section{Data availability}

The data that support the findings of this work are available from the corresponding author upon reasonable request.

Received: 29 February 2020; Accepted: 14 September 2020; Published online: 06 October 2020

\section{References}

1. Dunn, B., Kamath, H. \& Tarascon, J.-M. Electrical energy storage for the grid: a battery of choices. Science 334, 928-935 (2011).

2. Posada, J. O. G. et al. Aqueous batteries as grid scale energy storage solutions. Renew. Sustain. Energy Rev. 68, 1174-1182 (2017).

3. Choi, J. W. \& Aurbach, D. Promise and reality of post-lithium-ion batteries with high energy densities. Nat. Rev. Mater. 1, 16013 (2016).

4. Bruce, P. G., Freunberger, S. A., Hardwick, L. J. \& Tarascon, J.-M. Li- $\mathrm{O}_{2}$ and Li-S batteries with high energy storage. Nat. Mater. 11, 19 (2011).

5. Yang, X., Wang, H., Yu, D. Y. W. \& Rogach, A. L. Vacuum calcination induced conversion of selenium/carbon wires to tubes for high-performance sodium-selenium batteries. Adv. Funct. Mater. 28, 1706609 (2018).

6. Yao, Y. et al. CNT interwoven nitrogen and oxygen dual-doped porous carbon nanosheets as free-standing electrodes for high-performance Na-Se and K-Se flexible batteries. Adv. Mater. 30, 1805234 (2018).

7. Li, Z., Yuan, L., Yi, Z., Liu, Y. \& Huang, Y. Confined selenium within porous carbon nanospheres as cathode for advanced Li-Se batteries. Nano Energy 9 , 229-236 (2014).

8. Yang, C.-P. et al. An advanced selenium-carbon cathode for rechargeable lithium-selenium batteries. Angew. Chem. Int. Ed. 52, 8363-8367 (2013).

9. Lee, J. T. et al. Micro- and mesoporous carbide-derived carbon-selenium cathodes for high-performance lithium selenium batteries. Adv. Energy Mater. 5, 1400981 (2015).

10. Cui, Y. et al. (De)lithiation mechanism of $\mathrm{Li} / \mathrm{SeS}_{x}(\mathrm{x}=0-7)$ batteries determined by in situ synchrotron X-ray diffraction and X-ray absorption spectroscopy. J. Am. Chem. Soc. 135, 8047-8056 (2013).

11. Abouimrane, A. et al. A new class of lithium and sodium rechargeable batteries based on selenium and selenium-sulfur as a positive electrode. J. Am. Chem. Soc. 134, 4505-4508 (2012).

12. Luo, C. et al. Selenium@mesoporous carbon composite with superior lithium and sodium storage capacity. ACS Nano 7, 8003-8010 (2013).

13. Xin, S. et al. The electrochemistry with lithium versus sodium of selenium confined to slit micropores in carbon. Nano Lett. 16, 4560-4568 (2016).

14. Liu, T. et al. Selenium embedded in metal-organic framework derived hollow hierarchical porous carbon spheres for advanced lithium-selenium batteries. ACS Appl. Mater. Interfaces 8, 16063-16070 (2016).

15. Tian, $\mathrm{H}$. et al. Tunable porous carbon spheres for high-performance rechargeable batteries. J. Mater. Chem. A 6, 12816-12841 (2018).

16. Zeng, L. et al. A flexible porous carbon nanofibers-selenium cathode with superior electrochemical performance for both Li-Se and Na-Se batteries. Adv. Energy Mater. 5, 1401377 (2015).
17. Qu, Y. et al. Confining selenium in nitrogen-containing hierarchical porous carbon for high-rate rechargeable lithium-selenium batteries. J. Mater. Chem. A 2, 12255-12261 (2014).

18. Zhang, J. et al. Selenium/interconnected porous hollow carbon bubbles composites as the cathodes of Li-Se batteries with high performance. Nanoscale 6, 12952-12957 (2014).

19. Wang, A., Li, J. \& Zhang, T. Heterogeneous single-atom catalysis. Nat. Rev. Chem. 2, 65-81 (2018).

20. Guo, X. et al. Direct, nonoxidative conversion of methane to ethylene, aromatics, and hydrogen. Science 344, 616-619 (2014).

21. Zhang, J. et al. Single platinum atoms immobilized on an MXene as an efficient catalyst for the hydrogen evolution reaction. Nat. Catal. 1, 985-992 (2018).

22. Yang, L., Shi, L., Wang, D., Lv, Y. \& Cao, D. Single-atom cobalt electrocatalysts for foldable solid-state Zn-air battery. Nano Energy 50, 691-698 (2018)

23. Zang, W. et al. Single Co atoms anchored in porous $\mathrm{N}$-doped carbon for efficient zinc-air battery cathodes. ACS Catal. 8, 8961-8969 (2018).

24. Wang, J. et al. Single-atom catalyst boosts electrochemical conversion reactions in batteries. Energy Storage Mater. 18, 246-252 (2019).

25. Zhang, B.-W. et al. Atomic cobalt as an efficient electrocatalyst in sulfur cathodes for superior room-temperature sodium-sulfur batteries. Nat. Commun. 9, 4082 (2018).

26. Du, Z. et al. Cobalt in nitrogen-doped graphene as single-atom catalyst for high-sulfur content lithium-sulfur batteries. J. Am. Chem. Soc. 141, 3977-3985 (2019).

27. Qu, Y. et al. Direct transformation of bulk copper into copper single sites via emitting and trapping of atoms. Nat. Catal. 1, 781-786 (2018).

28. Wang, X. et al. Regulation of coordination number over single Co sites: triggering the efficient electroreduction of $\mathrm{CO}_{2}$. Angew. Chem. Int. Ed. 57, 1944-1948 (2018)

29. Li, J. et al. Atomically dispersed manganese catalysts for oxygen reduction in proton-exchange membrane fuel cells. Nat. Catal. 1, 935-945 (2018).

30. Chong, L. et al. Ultralow-loading platinum-cobalt fuel cell catalysts derived from imidazolate frameworks. Science 362, 1276-1281 (2018)

31. Zhong, H. et al. ZIF-8 derived graphene-based nitrogen-doped porous carbon sheets as highly efficient and durable oxygen reduction electrocatalysts. Angew. Chem. Int. Ed. 53, 14235-14239 (2014).

32. Chen, Y. et al. From bimetallic metal-organic framework to porous carbon: high surface area and multicomponent active dopants for excellent electrocatalysis. Adv. Mater. 27, 5010-5016 (2015).

33. Liu, D., Wan, J., Pang, G. \& Tang, Z. Hollow metal-organic-framework micro/ nanostructures and their derivatives: emerging multifunctional materials. $A d v$. Mater. 31, 1803291 (2018).

34. Nai, J. \& Lou, X. W. Hollow structures based on prussian blue and its analogs for electrochemical energy storage and conversion. Adv. Mater. 31, 1706825 (2018).

35. Wang, J., Cui, Y. \& Wang, D. Design of hollow nanostructures for energy storage, conversion and production. Adv. Mater. 31, 1801993 (2018).

36. Tian, $\mathrm{H}$. et al. Enhanced hydrogenation performance over hollow structured Co-CoOx@N-C capsules. Adv. Sci. 6, 1900807 (2019).

37. Tian, H., Liang, J. \& Liu, J. Nanoengineering carbon spheres as nanoreactors for sustainable energy applications. Adv. Mater. 31, 1903886 (2019).

38. Yin, P. et al. Single cobalt atoms with precise $\mathrm{N}$-coordination as superior oxygen reduction reaction catalysts. Angew. Chem. Int. Ed. 55, 10800-10805 (2016).

39. Yi, Z. et al. High-performance lithium-selenium batteries promoted by heteroatom-doped microporous carbon. J. Mater. Chem. A 3, 3059-3065 (2015)

40. Li, Z. \& Yin, L. MOF-derived, N-doped, hierarchically porous carbon sponges as immobilizers to confine selenium as cathodes for Li-Se batteries with superior storage capacity and perfect cycling stability. Nanoscale 7, 9597-9606 (2015).

41. Tian, H. et al. The development of yolk-shell-structured Pd\&ZnO@carbon submicroreactors with high selectivity and stability. Adv. Funct. Mater. 28, 1801737 (2018)

42. Wang, Q. et al. NiFe layered double hydroxide nanoparticles on Co,Ncodoped carbon nanoframes as efficient bifunctional catalysts for rechargeable zinc-air batteries. Adv. Energy Mater. 7, 1700467 (2017).

43. Tian, $\mathrm{H}$. et al. Metal-organic-framework-derived formation of $\mathrm{Co}-\mathrm{N}$-doped carbon materials for efficient oxygen reduction reaction. J. Energy Chem. 40, 137-143 (2020).

44. $\mathrm{Lu}, \mathrm{Z}$. et al. An isolated zinc-cobalt atomic pair for highly active and durable oxygen reduction. Angew. Chem. Int. Ed. 58, 2622-2626 (2019).

45. Cheng, Q. et al. Single cobalt atom and N codoped carbon nanofibers as highly durable electrocatalyst for oxygen reduction reaction. ACS Catal. 7, 6864-6871 (2017).

46. Han, X. et al. Generation of nanoparticle, atomic-cluster, and single-atom cobalt catalysts from zeolitic imidazole frameworks by spatial isolation and their use in zinc-air batteries. Angew. Chem. Int. Ed. 131, 5413-5418 (2019). 
47. Ye, H., Yin, Y.-X., Zhang, S.-F. \& Guo, Y.-G. Advanced Se-C nanocomposites: a bifunctional electrode material for both $\mathrm{Li}-\mathrm{Se}$ and $\mathrm{Li}$-ion batteries. J. Mater. Chem. A 2, 13293-13298 (2014).

48. Li, X. et al. A new salt-baked approach for confining selenium in metal complex-derived porous carbon with superior lithium storage properties. $A d v$. Funct. Mater. 25, 5229-5238 (2015).

49. Liu, Y. et al. A selenium-confined microporous carbon cathode for ultrastable lithium-selenium batteries. J. Mater. Chem. A 2, 17735-17739 (2014).

50. Zeng, L. et al. Green synthesis of a Se/HPCF-rGO composite for Li-Se batteries with excellent long-term cycling performance. J. Mater. Chem. A 5, 22997-23005 (2017).

51. Zhou, Y., Li, Z. \& Lu, Y.-C. A stable lithium-selenium interface via solid/ liquid hybrid electrolytes: blocking polyselenides and suppressing lithium dendrite. Nano Energy 39, 554-561 (2017)

52. Han, K. et al. A free-standing and ultralong-life lithium-selenium battery cathode enabled by 3D mesoporous carbon/graphene hierarchical architecture. Adv. Funct. Mater. 25, 455-463 (2015).

53. Zhang, H., Yu, F., Kang, W. \& Shen, Q. Encapsulating selenium into macro-/ micro-porous biochar-based framework for high-performance lithiumselenium batteries. Carbon 95, 354-363 (2015).

54. Augustyn, V. et al. High-rate electrochemical energy storage through $\mathrm{Li}^{+}$ intercalation pseudocapacitance. Nat. Mater. 12, 518 (2013).

55. Ding, J., Zhou, H., Zhang, H., Tong, L. \& Mitlin, D. Selenium impregnated monolithic carbons as free-standing cathodes for high volumetric energy lithium and sodium metal batteries. Adv. Energy Mater. 8, 1701918 (2018).

56. Chen, Z. et al. General synthesis of dual carbon-confined metal sulfides quantum dots toward high-performance anodes for sodium-ion batteries. Adv. Funct. Mater. 27, 1702046 (2017).

57. Wang, X. et al. New insight into the confinement effect of microporous carbon in Li/Se battery chemistry: a cathode with enhanced conductivity. Small 16, 2000266 (2020).

58. Liu, F. et al. A mixed lithium-ion conductive $\mathrm{Li}_{2} \mathrm{~S} / \mathrm{Li}_{2} \mathrm{Se}$ protection layer for stable lithium metal anode. Adv. Funct. Mater. 30, 2001607 (2020).

59. Yang, L. et al. Hierarchical $\mathrm{MoO}_{2} / \mathrm{Mo}_{2} \mathrm{C} / \mathrm{C}$ hybrid nanowires as high-rate and long-life anodes for lithium-ion batteries. ACS Appl. Mater. Interfaces 8, 19987-19993 (2016).

60. $\mathrm{Gu}, \mathrm{X}$. et al. Highly reversible Li-Se batteries with ultra-lightweight $\mathrm{N}, \mathrm{S}$ codoped graphene blocking layer. Nano-Micro Lett. 10, 59 (2018).

61. Lang, R. et al. Non defect-stabilized thermally stable single-atom catalyst. Nat. Commun. 10, 234 (2019).

62. Piernavieja-Hermida, M. et al. Towards ALD thin film stabilized single-atom $\mathrm{Pd}_{1}$ catalysts. Nanoscale 8, 15348-15356 (2016).

63. Han, A. et al. A polymer encapsulation strategy to synthesize porous nitrogendoped carbon-nanosphere-supported metal isolated-single-atomic-site catalysts. Adv. Mater. 30, 1706508 (2018).

64. Liu, P. et al. Photochemical route for synthesizing atomically dispersed palladium catalysts. Science 352, 797-800 (2016).

65. Kohn, W. \& Sham, L. J. Self-consistent equations including exchange and correlation effects. Phys. Rev. 140, A1133-A1138 (1965).

66. Perdew, J. P., Burke, K. \& Ernzerhof, M. Generalized gradient approximation made simple. Phys. Rev. Lett. 77, 3865-3868 (1996).

67. Monkhorst, H. J. \& Pack, J. D. Special points for brillouin-zone integrations. Phys. Rev. B 13, 5188-5192 (1976).
68. $\mathrm{Xu}, \mathrm{Z}$. et al. First principles study of adsorption and oxidation mechanism of elemental mercury by $\mathrm{HCl}$ over $\mathrm{MoS}_{2}$ (100) surface. Chem. Eng. J. 308, 1225-1232 (2017).

69. Lv, X., Xu, Z., Li, J., Chen, J. \& Liu, Q. Investigation of fluorine adsorption on nitrogen doped $\mathrm{MgAl}_{2} \mathrm{O}_{4}$ surface by first-principles. Appl. Surf. Sci. 376, 97-104 (2016).

\section{Acknowledgements}

Prof. Hao Liu thanks the support of the ARC Future Fellowship (FT180100705) and Discovery Project (DP180102297). This work was partially supported by the DNL Cooperation Fund, CAS (DNL180402).

\section{Author contributions}

H.T. and H.J.T. contributed equally to this work. H.L., J.L. and G.X.W. designed the research. H.T. synthesized and characterized the prepared materials. H.T., H.J.T., S.J.W and F.Z. performed the electrochemical performances. S.M.C. and L.S. carried out the XAFS characterization. H.T., H.J.T., H.L. and J.L. co-wrote the paper with input from S.J. W., F.Z., S.M.C., L.S. and G.X.W. for analysis of the data and preparation of this paper. The paper was revised by all authors.

\section{Competing interests}

The authors declare no competing interests.

\section{Additional information}

Supplementary information is available for this paper at https://doi.org/10.1038/s41467020-18820-y.

Correspondence and requests for materials should be addressed to L.S., H.L., J.L. or G.W

Peer review information Nature Communications thanks the anonymous reviewers for their contribution to the peer review of this work. Peer reviewer reports are available.

Reprints and permission information is available at http://www.nature.com/reprints

Publisher's note Springer Nature remains neutral with regard to jurisdictional claims in published maps and institutional affiliations.

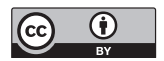

Open Access This article is licensed under a Creative Commons Attribution 4.0 International License, which permits use, sharing, adaptation, distribution and reproduction in any medium or format, as long as you give appropriate credit to the original author(s) and the source, provide a link to the Creative Commons license, and indicate if changes were made. The images or other third party material in this article are included in the article's Creative Commons license, unless indicated otherwise in a credit line to the material. If material is not included in the article's Creative Commons license and your intended use is not permitted by statutory regulation or exceeds the permitted use, you will need to obtain permission directly from the copyright holder. To view a copy of this license, visit http://creativecommons.org/licenses/by/4.0/.

(c) The Author(s) 2020 